\title{
EL MUSEO: UN ESPACIO EDUCATIVO PARA LA IGUALDAD SOCIAL. EL CASO PIONERO DEL MUSEO PEDAGÓGICO NACIONAL EN ESPAÑA (1882-1941)
}

\author{
The Museum: An Educational Space for Social Equality. The Pioneer \\ Case of the National Pedagogic Museum in Spain (1882-1941)
}

\author{
Javier Mateo de Castro \\ jmateodecastro@gmail.com \\ Universidad Complutense de Madrid. España
}

Fecha de recepción: 01/05/2017

Fecha de aceptación: 18/09/2017

RESUMEN: Este trabajo de investigación analiza el papel del Museo Pedagógico Nacional en la redefinición del modelo de museo y de la educación española. La importancia de esta institución radica en el convencimiento de los responsables del museo -miembros de la Institución Libre de Enseñanza- de la centralidad de la cuestión educativa en la transición de la sociedad española hacia un sistema social más equitativo. Partiendo de esta hipótesis, los objetivos de este trabajo son definir el sustrato conceptual que impulsó el surgimiento de este museo y su funcionamiento; describir la transformación del modelo museístico que estos postulados implicaron y, por último, analizar algunas de las propuestas museográficas dirigidas por este centro con la intención de fomentar la igualdad a través de la educación. La metodología de trabajo consiste en un procedimiento ordenado deductivo. Partiendo de un marco teórico que analiza el papel de la educación en la igualdad y la situación española en ese contexto temporal, se relacionan los postulados de los institucionistas con el diseño del museo en su conjunto para finalizar con el análisis del impacto de los mismos a través del estudio de dos casos concretos: las dos exposiciones de bordados celebradas en 1913 y 1915. Las fuentes incluyen varios escritos de Manuel Bartolomé Cossío, director del Museo, así como numerosas referencias procedentes del ámbito de la museología. La actual vigencia de la educación como una de las funciones propias del museo evidencia la pertinencia histórica de los aspectos tratados, erigiéndose en su principal conclusión.

Palabras clave: Igualdad social; Museo; Educación; Institución Libre de Enseñanza. 
ABSTRACT: This research analyses the National Pedagogic Museum's role in the redefinition of both the museum model and the Spanish education model. The importance of this institution resides in the conviction held by museum employees, members of the Institución Libre de Enseñanza, regarding the significance of education in the transition to a more equitable social system. Building upon this hypothesis, the objectives of this research are, firstly, to define the conceptual basis that gave life to this museum and its operation; secondly, to describe the transformation of the museum model that these postulates implied; and lastly, to study some of the Museum's museographic proposals intended to promote equality through education. The research methodology consists in an ordered deductive process. From the starting point of a theoretical framework analysing the role of education in achieving equality and the state of Spanish education in the context of that moment, institutional members' postulates are related to the museum's overall design, producing an analysis of their impact through a study of two specific cases: those of the embroidery works exhibitions celebrated in 1913 and in 1915. Source materials include some writings of museum director Manuel Bartolomé Cossío, as well as numerous references from the field of museology. The current importance of education as proper to the museum's role is evidence of the historical pertinence of the aspects discussed herein, becoming the principal conclusion hereof.

Keywords: Social equality; Museums; Education; Institución Libre de Enseñanza.

SUMARIO: 1. La educación, un arma contra la desigualdad. 2. Educación y museos en la España del cambio de siglo. 3. Un debate histórico: el museo, ¿̇un espacio para la élite o para todos? 4. La ILE y el museo. El papel de Manuel Bartolomé Cossío. 5. El museo, legitimador de la ciencia pedagógica. 6 . La acción educativa, legitimadora del museo. 7. Una nueva organización para una institución renovada. 8. El museo como plataforma inclusiva de promoción social: las exposiciones de bordados de 1913 y 1915. 9. Recursos bibliográficos y documentales.

«La memoria es una construcción del futuro, más que del pasado»

Murilo Mendes

\section{LA EDUCACIÓN, UN ARMA CONTRA LA DESIGUALDAD}

Como sabemos, la educación es un factor clave en el avance hacia sociedades más igualitarias económica y socialmente. En este sentido, los indicadores de la OCDE, publicados bajo el título Panorama de la educación 2014. Indicadores de la OCDE (Martín, 2014), evidencian el impacto de la educación en ámbitos determinantes en el camino hacia la igualdad, entendiendo por tal, por un lado, la disminución de las diferencias económicas, y por el otro, la formación de una ciudadanía rica en valores que, entre otros aspectos, combata todo tipo de exclusión.

En primer lugar, en la sección destinada al estudio de la influencia de la educación en la situación económica de los ciudadanos, los estudios inciden en la relación entre la mejora del stock educativo y la modernización y el crecimiento de la economía (Núñez, 2005, p. 175). En este sentido, los estudios de la OCDE han probado que 
el desempleo alcanza una diferencia media de veinte puntos entre los ciudadanos con un nivel educativo alto y aquellos con un nivel educativo bajo, en el que la tasa de empleo desciende hasta un 60\%, fomentando enormemente la perpetuación de diferencias sociales por causas económicas (Martín, 2014, p. 112). Se han propuesto dos teorías a la hora de justificar esta dinámica. La primera ve en la educación la transmisión de una serie de conocimientos y el desarrollo de distintas competencias en el ciudadano, que lo habilitarían para el desempeño de un empleo. En otras palabras, los procesos educativos servirían para dotar al trabajador del «conjunto de capacidades, destrezas, saberes, información, actitudes, etc.» necesarias para el trabajo (Fernández, 1990, p. 6). La segunda teoría, enunciada por Bordieu y Passeron mediante su modelo diacrónico de las trayectorias escolares, ve en el sistema escolar una suerte de institución legitimadora destinada a la producción y a la distribución de títulos socialmente valorizados, esto es, de atributos sociales intergeneracionales (Brunet y Pastor, 2002, p. 19). De este modo, el sistema educativo contribuiría a reproducir y legitimar el conjunto de las diferencias que constituyen, en cada momento, la estructura social, relacionándose así con el concepto de violencia simbólica. Probablemente ambas posturas operen al mismo tiempo en nuestras sociedades, pero pese a lo interesante del debate, no figura entre los objetivos de este trabajo apoyar una u otra teoría. Sí que lo hace, sin embargo, defender la centralidad de la educación en el combate contra la desigualdad, sea mediante la capacitación de los individuos o a través de la lógica de la categorización social. Pese a lo dicho, debe afirmarse que la visión del proceso educativo de los miembros de la Institución Libre de Enseñanza (ILE en adelante) -responsables de la fundación del Museo Pedagógico Nacional- bebía directamente del krausismo, y aludía por ello constantemente a la formación del espíritu, esto es, de la cualificación del ciudadano, antes que de lógicas de dominación y de clase, como posteriormente veremos.

Continuando con los resultados del análisis de la OCDE, queda en él demostrado igualmente que la formación no solo favorece a los individuos, «sino que la población en general también se beneficia de una mayor proporción de personas con educación terciaria a través de una mayor recaudación fiscal y cotizaciones (...) a través de un menor gasto público en programas de bienestar social» (Martín, 2014, p. 160). Es decir, las sociedades más formadas son más sostenibles económicamente que las que tienen estándares de educación inferiores, al favorecer aquellas la creación de empleo y reduciendo así el número de ciudadanos dependientes de los servicios sociales para su supervivencia y permitiendo la redistribución efectiva de los ingresos por el Estado, fomentando la sostenibilidad de numerosas políticas de bienestar. Además, los estudios que venimos mencionando han evidenciado que las diferencias en el acceso al empleo son aún mayores cuando se introduce la variable del sexo: la tasa de desempleo es mayor en las mujeres que en los hombres en todos los niveles educativos, pero se ha demostrado que las diferencias disminuyen de forma gradual con el nivel educativo: desde un sangrante $20 \%$ en el grupo con educación secundaria 
inferior, hasta el nivel educativo superior, donde se mantienen unas diferencias entre géneros del 10\%, siempre en perjuicio del colectivo femenino (Martín, 2014, p. 112). En relación a este problema, recientes estudios referidos en medios de comunicación de nuestro país han activado la alarma. Como apunta el diario El País de 8 de marzo de 2015, los datos publicados por la agencia estadística de Bruselas, Eurostat, indican que «la retribución media de las mujeres españolas fue un 18,8\% inferior a la de los hombres en 2014» (Bolaños, 2016), y El Diario de 27 de julio de 2016 cita el avance de resultados de la Encuesta de Estructura Salarial 2014 del INE (Instituto Nacional de Estadística), en el que se concluye que «las mujeres son mayoría entre quienes perciben los salarios más bajos. De quienes en 2014 ganaban entre 0 y 1 vez el SMI [Salario Mínimo Interprofesional], 7 de cada 10 eran mujeres; y de quienes ganaban entre 1 y 2 veces el SMI, el 54\% también son mujeres. La pobreza laboral tiene rostro de mujer» (Herranz, 2017). Los datos evidencian la necesidad de tomar cuantas medidas sean oportunas para combatir la desigualdad de género y de formar a jóvenes concienciados con esta problemática. También en este punto los institucionistas anticiparon algunas de las políticas activas que hoy combaten la desigualdad de género, tal y como veremos posteriormente al analizar el impacto de las exposiciones de bordados puestas en marcha por el Museo Pedagógico.

Sin embargo, la evidencia del impacto de la educación en lo referente a las desigualdades sociales no se detiene en el ámbito económico. Los resultados del estudio de la OCDE corroboran la importancia de la educación en el progreso hacia sociedades más maduras, responsables y concienciadas. Así, el informe del año 2014 afirma que «tanto el nivel educativo como la comprensión lectora están fuertemente asociados a elevados niveles de resultados sociales, incluyendo la percepción subjetiva del estado de salud, el voluntariado, la confianza interpersonal y la eficacia política» (Martín, 2014, p. 182).

En este sentido, la diferencia en la proporción de ciudadanos que dicen participar en actividades de voluntariado es diez puntos superior entre aquellos con un nivel educativo alto y los que tienen un nivel bajo, y entre estos, de ocho puntos entre los que tienen una buena comprensión lectora y los que no (Martín, 2014, p. 184). También en el ámbito de la eficacia política -entendiéndose por tal el porcentaje de ciudadanos que dice estar en desacuerdo con la aseveración "La gente como yo no tiene voz sobre lo que haga el gobierno»- la influencia de la educación es muy significativa: veinte puntos entre aquellos que disfrutan de un nivel educativo alto frente a los que lo hacen de un nivel bajo (Martín, 2014, p. 186). Igualmente, el estudio incide en la significativa relación existente entre el nivel educativo -y la compresión lectora- y aspectos como la confianza interpersonal o la percepción del estado de salud, con lo que esto implica en el desarrollo de diversas políticas públicas. La vinculación de los resultados del análisis de la OCDE con los posicionamientos insitucionistas es, al igual que en el caso de las desigualdades económicas, sencillo de demostrar. Los miembros de la ILE mostraban una confianza roussoniana en la 
naturaleza humana que, según Manuel Bartolomé Cossío (Figura 1), uno de sus más insignes miembros, precisaría en un primer momento, para aspirar a lo bello, a lo bueno, de directores que se ocupasen de educarla (Garrido y Pinto, 1996, p. 153). Este posicionamiento de los institucionistas les llevó, entre otras cosas, a extender los programas de educación a las capas poblacionales menos educadas mediante las Misiones Pedagógicas de la II República, cuya dirección fue encomendada al Museo Pedagógico.

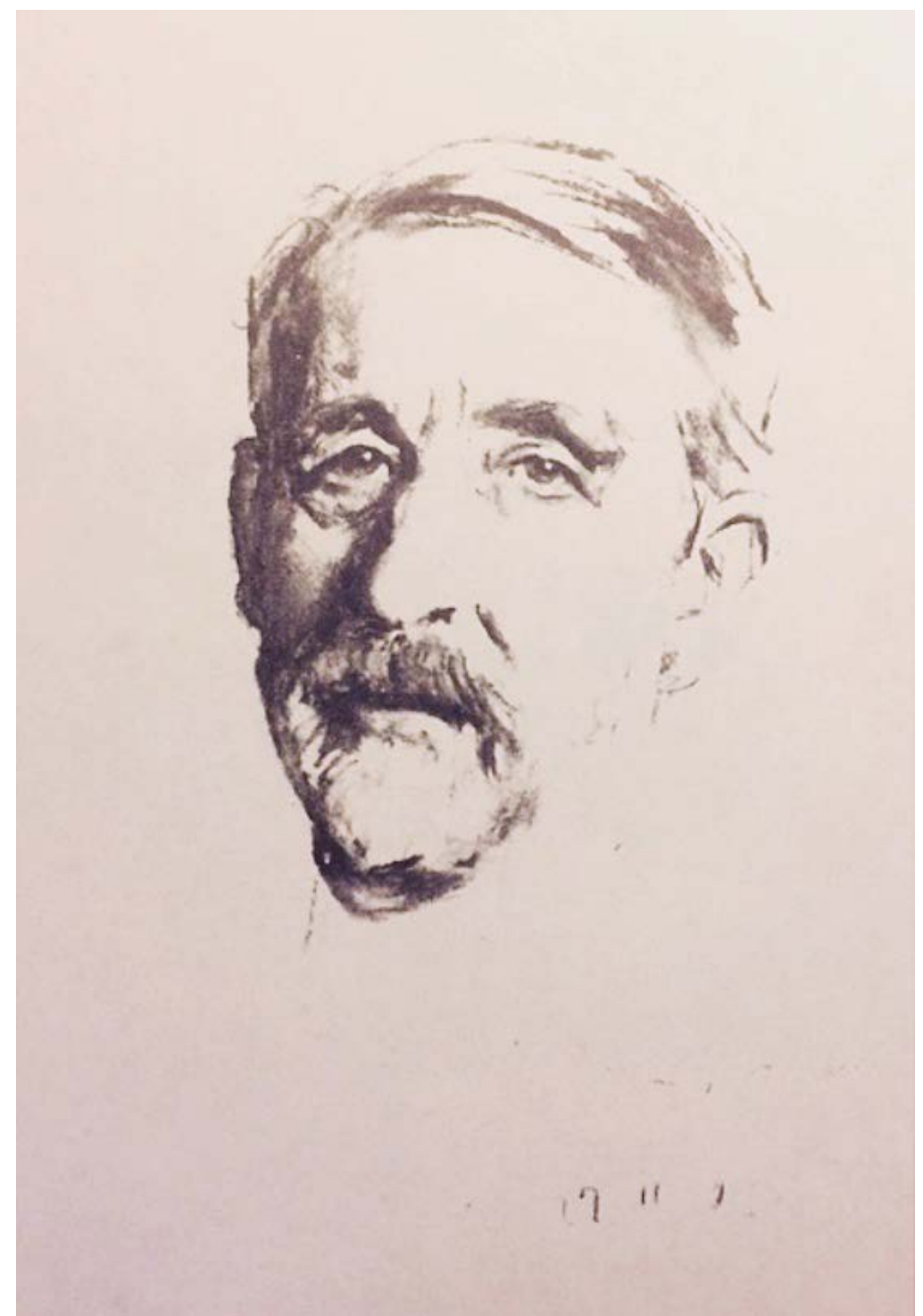

Figura 1. Retrato de Manuel Bartolomé Cossío. Leandro Oroz Lacalle, 1926. Lápiz sobre papel. Colección particular. 
Para concluir este apartado, conviene indicar que, pese a evidenciar magistralmente la necesidad de un sistema educativo vigoroso y eficiente a la hora de combatir la desigualdad en sus distintas vertientes, los estudios de la OCDE, al igual que la inmensa mayoría de los análisis normativizados a gran escala, albergan una gran debilidad, justificable dada la enorme diversidad de variables medidas y de países participantes en el estudio: la delimitación del estudio del impacto de la actividad educativa al ámbito reglado. Es decir, la restricción de su enfoque al ámbito escolar, universitario y de formación profesional, sin considerar el impacto que otras entidades sociales tienen en el proceso de la educación en la sociedad y, por tanto, en la extensión de la igualdad, como ocurre en el caso de los museos. Sí que existen, sin embargo, numerosos estudios que evidencian los beneficios de la educación en estas instituciones. A modo de ejemplo, puede citarse el texto Los museos en la educación, resultado de la publicación de un conjunto de ponencias realizadas en el Museo ThyssenBornemisza en el contexto del exitoso congreso internacional homónimo (Arnaldo, 2009). A lo largo de este estudio se analizará el primer museo concebido como espacio para la educación en España: el Museo Pedagógico Nacional, trazándose paralelismos entre algunas de sus prácticas pioneras y otras desarrolladas en el presente. La oportunidad de acometer el estudio de esta institución puesta en marcha por la Institución Libre de Enseñanza no se debe solo a su papel precursor de algunas de las prácticas museográficas hoy normalizadas en el ámbito de los museos, sino, muy especialmente, por haberlo hecho en un momento en el que nuestro país era uno de los más desiguales de Europa. Es este un hecho que dota de pleno interés y contemporaneidad a este estudio, toda vez que España ha devenido en «el país más desigual de la OCDE» («España, el país más desigual de la OCDE», 2016).

\section{EDUCACIÓN Y MUSEOS EN LA ESPAÑA DEL CAMBIO DE SIGLO}

Seis de cada diez ciudadanos españoles eran analfabetos a principios del siglo xx. Vista la relación que la OCDE ha demostrado en sus estudios entre el nivel formativo de los ciudadanos y la igualdad socioeconómica en las sociedades que conforman, quizá ahora resulten aún más claros los datos de desigualdad que asolaban nuestro país en aquella época. Como ha recogido Clara Eugenia Núñez (2005), la recuperación de la crisis inicial del siglo xIX fue acompañada de una serie de cambios de gran alcance que supusieron, entre otros aspectos, la transición de un modelo de alfabetización en el que, además de la lectura, se potenciaba el dominio de la escritura; la incorporación definitiva de las mujeres a la escuela y la organización paulatina del sistema educativo en los tres niveles que actualmente se mantienen. Estos hechos, acompañados de un periodo 
de expansión educativa que duró más de cuatro décadas, consiguieron que, frente al 78\% de la generación de 1832 que no contaba con estudios, el índice se redujese al $51 \%$ en la de 1876 . Sin embargo, las tres últimas décadas del siglo supondrían un estancamiento en esta dinámica, aumentando al $58 \%$ en la generación de 1907 y superando la generación de 1915 a la de 1876 (Núñez, 2005, p. 164), alcanzando la ratio que daba inicio a este párrafo.

En este sentido, la crisis finisecular española hizo que la situación educativa de los albores del siglo $x x$ se encontrase en una situación enconada: "dentro del orden social era considerado un gasto superfluo e incluso pernicioso el dedicado a cualquier educación que se extendiera a las clases trabajadoras, campesinas u obreras, más allá de los rudimentos básicos que les permitieran cumplir con sus funciones» (García, 2015, p. 76). Los datos no hacen sino corroborar esta afirmación tanto desde el punto de vista cualitativo como desde el cuantitativo: se ha estimado que más de la tercera parte de los maestros carecía de la titulación correspondiente, y que la inmensa mayoría vivía con sueldos mezquinos. A estos factores se unían, además, la limitadísima formación que recibían los docentes en las Escuelas Normales, encargados de formar a los profesores; el déficit de escuelas, estimado en más de 4.000; las condiciones de habitabilidad -luz, calefacción, espacio y mobiliario, etc.- de las existentes y la práctica ausencia de materiales de enseñanza. La combinación de estos factores impedía la aplicación práctica de los contenidos teóricos y reducía la educación a la transmisión unidireccional de contenidos, que debían retenerse no a través de su comprensión y puesta en práctica, sino únicamente mediante la repetición memorística.

En suma, la educación primaria se encontraba en un estado de total abandono y la Iglesia, erigida en cerbero de un sistema desigual, se preocupaba de regir la educación secundaria. El posicionamiento del catolicismo institucional español debe comprenderse en términos del enfrentamiento que acontecía en aquellos años por el control del motor espiritual, emocional del país. En un Estado en el que la enseñanza superior -terciaria, universitaria- se mostraba incapaz de emprender el camino hacia el progreso que la sociedad requería a través de la ciencia y en el que el grueso de la población veía finalizado su proceso formativo en la escuela, dominar la gestión, el discurso y los métodos de esta era una cuestión de primerísimo orden a la hora de definir y dar solidez a las estructuras sociales. Como afirma María García (2015, pp. 81-82), la Iglesia comprendió desde los primeros compases del proceso que el avance intelectual republicano, materializado en la ingente creación de escuelas públicas y en el surgimiento de instituciones como las Misiones Pedagógicas o el propio Museo Pedagógico Nacional, venía 
a activar un circuito de emociones ligado a un nuevo sentimiento ciudadano, que tenía notorios puntos en contacto con algunos fenómenos religiosos a los que sustituía. (...) La conversión de todo hombre moderno en un misionero, de todo Estado en servidor y propagador de alguna idea coincide en el mundo contemporáneo con una sutil infiltración del discurso religioso en la vida política y cultural. Las escuelas se transforman en templos; los intelectuales y artistas, en profetas capaces de despertar un tipo de fervor laico inédito (...).

Afirmar que el origen de las enormes discrepancias existentes en el debate educativo se encontraba en los métodos de enseñanza sería, por tanto, parcial e inexacto. Como venimos viendo, el trasfondo real de la confrontación era la re-definición del destino y de los sentimientos compartidos por la comunidad, y con ello de las estructuras constituyentes de esta o la conservación de las mismas, el mantenimiento del poder en las manos que lo ostentaban o el empoderamiento de nuevas capas sociales. En consecuencia, es en la lucha por la concepción del espíritu de la sociedad, en el combate por el control de los procesos de transmisión intergeneracional de las ideas, y por tanto de las estructuras sociales, donde nace el enfrentamiento en torno a las funciones y los medios de enseñanza. Y como veremos, esta tensión no solo incluirá a la institución tradicionalmente encargada de llevar a cabo la tarea educativa, la escuela, sino que se extenderá hasta la institución museística.

A la respuesta reaccionaria contra el surgimiento de un nuevo estatuto de la ciudadanía más igualitario, que dificultaba la puesta en marcha de proyectos que combatiesen las dinámicas transformadoras, se sumaba la carencia de recursos por parte del Estado, hecho que ahogaba toda ilusión de cambio aún cuando se había hallado el apoyo político a esa voluntad. En otras palabras, la ausencia de soluciones modernas a los problemas educativos se ha explicado como una suerte de círculo vicioso entre la economía y la educación: el retraso de la educación española se debería «al fracaso de la revolución burguesa española. La estructura económica (...) no demandaba del sistema educativo grandes reformas de carácter técnico y científico» (García del Dujo, 1985, p. 25). Por otra parte, pocos parecían compartir la opinión de que estaba en las manos de los educadores detener esa inercia incapacitante. Tras su viaje a Alemania en 1843 y el discurso pronunciado en la Universidad Central en 1857, será Julián Sanz del Río el primero en abordar el debate desde posturas progresistas, concretamente a través del ideario krausista, corriente de pensamiento que combatirá esta decadencia.

Surgen, de esta manera, dos bloques: los tradicionales, por lo general fieles a las posturas reaccionarias de la jerarquía católica, y los innovadores, encabezados por la Institución Libre de Enseñanza (ILE, en adelante), cuyos 
miembros procedían, casi en su totalidad, de la burguesía liberal. Los primeros pretenden que la educación mantenga intacta la estructura social mediante la defensa a ultranza del sistema de valores en el que se apoya, tarea que lógicamente debe hacerse a través de las metodologías educativas tradicionales, en las que el alumno-ciudadano asume el rol de receptor pasivo de mensajes previamente elaborados. Los segundos, que el sistema educativo empuje, en sus objetivos y sus procedimientos, a la sociedad hacia su necesaria transformación, promoviendo una revisión radical de ambos aspectos mediante una metodología renovadora que capacite al alumnado para participar de forma activa en el proceso educativo. De esta manera, frente a la postura de los tradicionales, que relegaba la educación al encorsetamiento del ciudadano como siervo, fiel y esposo, la ILE vendría a proponer, en línea con sus propósitos, un incremento de los presupuestos destinados a la educación y la implantación y el desarrollo de nuevas vías de aprendizaje, haciendo suyas las posturas de Pestalozzi, Fröbel y otros miembros de la Escuela Nueva. En este sentido, los testimonios de Manuel Bartolomé Cossío -alumno predilecto de Francisco Giner de los Ríos, miembro de la ILE y director del Museo Pedagógico Nacional- a tenor de la enseñanza de la Historia del Arte muestran una evidentísima sintonía con las tesis del aprendizaje significativo en el marco de la psicología constructivista, promulgadas por Ausubel, Novak y Hanesian en las décadas de 1960 y 1970: "Los ejemplos para que el niño se dé cuenta de aquellas ideas deben tomarse (...) de la observación de su propia vida, que es la historia que tiene más cerca (...) procurando que ordene y enlace unos puntos con otros y construya de este modo la serie entera (...) en una edad en que apenas ve ni goza más que con lo sensible» (Otero, 2007, pp. 171-173).

De forma paralela, durante siglo XIX los museos españoles evidencian una situación especialmente crítica. Si bien el modelo de museo público-que había tenido en el Louvre su ejemplo de institución al servicio de la sociedad- hacía aguas en la mayoría de los países occidentales, lo esperpéntico de la centuria española provocaba que nuestros museos se encontrasen en una situación penosa, amén de un retraso en las prácticas museográficas más novedosas (Figura 2). Así, el museo del XIX, anclado en el romanticismo decadente y el nacionalismo "retrospectivo, antes que utópico» (Bolaños, 2008, p. 243), víctima de sus orígenes y de la incapacidad de lo público para atenderlo, se mostraba incapaz de avanzar hacia un modelo que le diese la capacidad de promover el progreso científico-técnico propugnado por el positivismo historicista, a diferencia de lo que ocurría en Gran Bretaña y Centroeuropa, donde interesantísimos casos de museos de la artesanía y la industria fomentaban exitosamente el desarrollo económico del país, como veremos posteriormente. 


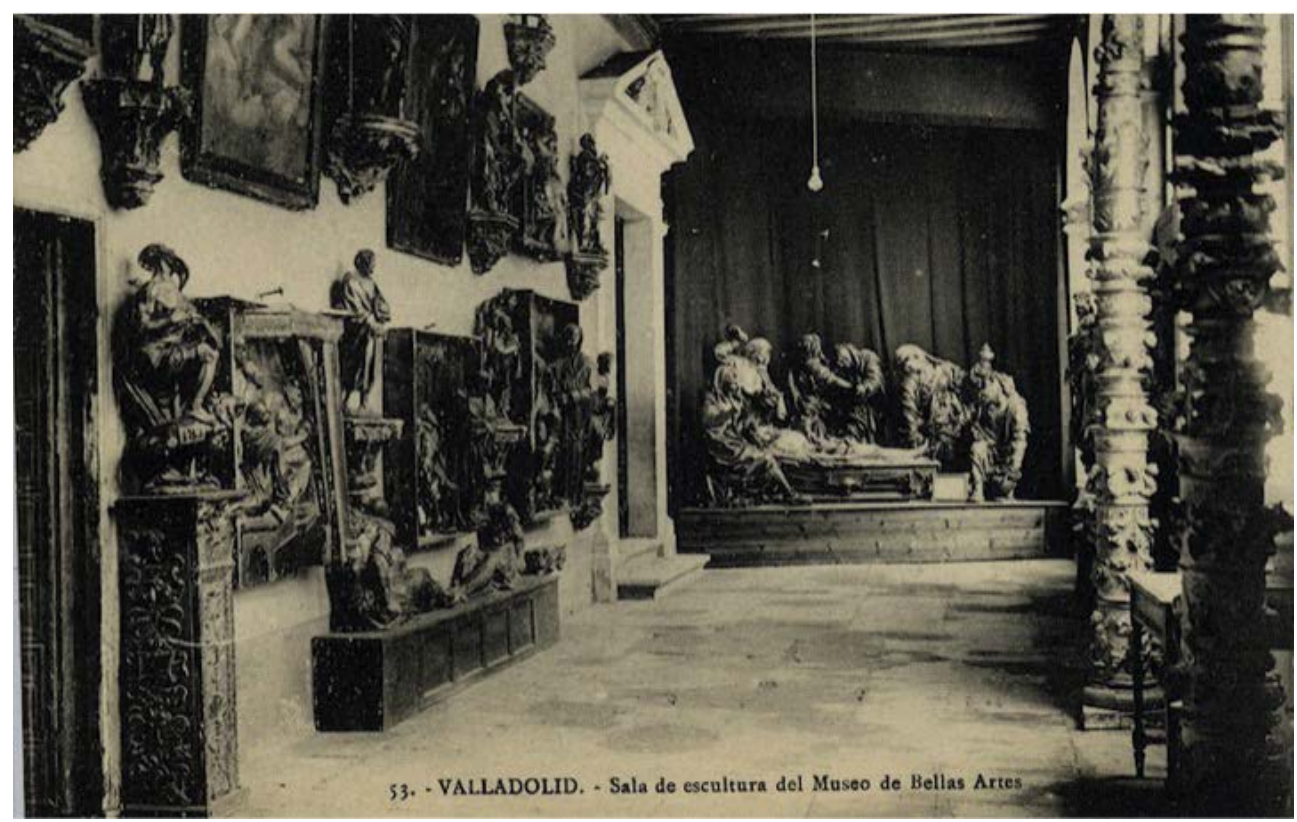

Figura 2. Museo provincial de Bellas Artes de Valladolid, c. 1915.

Al igual que en el anterior debate, surgen dos posturas ante la necesaria reforma de los museos y su relación con el tiempo pasado, el presente y el futuro. Siguiendo la trayectoria del Musée du Luxembourg, fundado en 1818 en París, los continuistas defendían la apertura controlada del ámbito cronológico de las colecciones del museo -incluyendo en las mismas al arte contemporáneo-, pero no la actualización de las funciones de la institución. La propuesta alcanzó su cima con la apertura del Museo de Arte Moderno en 1898, en el que se exponían cientos de primeras medallas (Bolaños, 2008, pp. 281-282) y cuyo recorrido se extendería pocas décadas ante el desinterés de la sociedad. El intento de modernización del museo mediante la extensión conceptual del término patrimonio histórico hasta el presente mediante la incorporación testimonial de una imagen estática del hoy, obtenida tras el filtro de este por una élite atávica, se mostraba, pues, fallido por su timidez e incongruencia. En el lado contrario, los rupturistas pretendían fraguar un nuevo modelo de museo que articulase un discurso científico ordenado, definido por Rada y Delgado como «el gran libro que los objetos antiguos exhiben a la investigación científica solo con presentarse en el orden progresivo con que los fue produciendo la actividad humana» (Bolaños, 2008, p. 242). Esta propuesta, verdaderamente renovadora, asumía que el relato debería incluir al tiempo presente a través de sus objetos, como defendían también los continuistas, pero que habría de hacerlo de forma simultánea a un segundo proceso irrenunciable: el empoderamiento del conjunto de la ciudadanía en la indagación e interpretación 
de los mismos, guiada en el proceso por profesionales extensamente cualificados. El objetivo de estas medidas no sería otro que la vinculación de la institución con el futuro, al otorgarle un papel fundamental en los proyectos de reforma del país, tan vinculados con la educación, la ciencia y las artes desde su enfoque. Y como ocurría en el debate educativo, destacará también en la reformulación del museo el papel de Cossío, aspecto tratado en el siguiente epígrafe.

Pese a estos esfuerzos, la debilidad del Estado y el atraso cultural español impidieron que se lograsen más que algunos tímidos avances inconexos, y la llegada del siglo xx se encontraría con el problema aún enquistado. En la cuna del museo moderno, Francia, siendo la situación mejor que la española, Paul Valéry atacaba en 1923 al museo, un lugar en el que «se despliega en silencio un extraño desorden organizado. Pronto dejo de saber a qué he venido a estas soledades enceradas, ¿̇He venido a instruirme, o a buscar algo que me encante, o bien a cumplir con un deber y satisfacer las apariencias?» (Valéry, 1999, pp. 137-140).

La cuestión parecía lejos de su resolución en el aspecto ontológico, y quizá debido a este motivo, ocurría lo mismo en el ámbito de la utilidad social del museo, aún sin satisfacer por parte de una institución que se mostraba inaccesible para la inmensa mayoría de la ciudadanía, quedando limitada a las incuestionables funciones de disfrute estético e investigación erudita. Como apuntaba décadas después Theodor Adorno (1962, pp. 189-190), la posición de Valéry presentaba

acentos resueltamente conservadores en cuestiones de cultura (...) No hay más reacción posible que la que Valéry considera como sombra general y de principio del progreso de dominio material de cualquier tipo: la superficialidad creciente. El arte se hace según el asunto de educación y de información, Venus se convierte en documento; y, en asuntos de arte, la educación le parece una derrota.

Las encontradas posiciones en torno al papel de la escuela y el museo en sociedades aquejadas de enormes desigualdades se debían tanto a las funciones tradicionalmente atribuidas a cada espacio como a un hecho derivado de aquello: sus incompatibles modos de operar. Merced a los progresos sociales y muy especialmente a los de la pedagogía, la escuela comenzaba a ser un lugar cada vez más accesible. Así lo atestiguan los datos de escolarización contemplados con perspectiva, en el que se otorgaba al ciudadano un papel cada vez más activo, como anteriormente hemos mencionado con el caso de la lectura y la escritura. Sin embargo, el museo continuaba siendo un espacio en el que el visitante debía enfrentarse, con sus propios recursos, a los resortes discriminatorios de la alta cultura, materializados aquí en el hermetismo del compendio de objetos, solo roto, $y$ no siempre, por las escuetas cartelas que se limitaban un dar un nombre, una fecha, una autoría. Una incomunicación que, ante la ausencia de una figura mediadora 
entre las obras y la ciudadanía, solo podían salvar aquellos visitantes dotados con las herramientas necesarias para desentrañar sus mensajes: el conocimiento en sus diversas vertientes -conceptos, procedimientos, actitudes-. Si tenemos en consideración que la extensión de este era administrada por un sistema educativo diseñado no en base a la universalidad sino a la clase, el distanciamiento del museo con la mayoría de la población resulta fácil de presumir. Veremos a continuación que la ILE, a través del Museo Pedagógico Nacional, jugó un papel imprescindible en la transformación del museo en un espacio social destinado tanto a la conservación como a la acción educativa mediante la formación continua del conjunto de la ciudadanía.

\section{UN DEBATE HISTÓRICO: EL MUSEO, ¿UN ESPACIO PARA LA ÉLITE O PARA TODOS?}

Un estudio que pretenda analizar la implicación del museo en el combate contra las desigualdades sociales, sea cual sea la naturaleza de estas, debe partir de la defensa de esta institución como una entidad destinada a la conservación del legado del pasado, pero debe también asumir que esta costosa función encuentra su justificación en la utilización de sus recursos para la promoción social en sus distintos ámbitos, muy especialmente a través de la educación. El museo debe estar, por tanto, siempre imbuido del deseo de generar una ciudadanía con altos estándares formativos. En este sentido, junto con la escuela, el museo ha participado desde sus orígenes en el desarrollo de las funciones sociales que nos definen como seres culturales: la promoción del saber y la preservación de nuestro legado. En el imaginario popular, la primera ha enfocado su función hacia la transmisión ininterrumpida e intergeneracional del conjunto de conocimientos que definen nuestra civilización; el segundo a la conservación de los vestigios de los relatos de la humanidad. Y a ellas se han sumado, a lo largo de la historia, instituciones como la universidad en la Edad Media y las diversas organizaciones cívicas que actualmente agrupamos bajo la denominación "tercer sector» y que velan por el progreso de distintos colectivos sociales. Sin embargo, restringir la función del museo a la conservación del pasado venía a significar la certificación de su desmantelamiento por inservible en la obligatoria conquista del futuro. Las palabras de Pomian (2007, pp. 163-164) explican a la perfección el proceso histórico al que se enfrentaban las instituciones de aquel momento:

Durante las últimas décadas del siglo XIX, en los países desarrollados de Europa y en Estados Unidos, y más tarde bajo otros cielos, llega a su fin el largo proceso histórico que transformó un mundo pasadista en un mundo futurista, un mundo en el que solo se pretendía reproducir lo que fuera, imitar 
respetuosamente los ejemplos que transmitía la tradición (...), en un mundo en el que el mayor prestigio recae en la innovación, la invención y el descubrimiento tanto en la economía como en las ciencias y en las técnicas; en el que se prima, en las artes, las letras e incluso en las costumbres, lo original, lo inédito, lo nunca visto.

Una de las críticas más incendiarias que se han publicado contra el modelo de museo que la ILE combatió desde sus posicionamientos intelectuales se encuentra en un ensayo publicado en 1953 y hoy convertido en uno de los textos referenciales de la ciencia museológica. En él, el filósofo Theodor W. Adorno lanzó una de las proclamas más incendiarias contra los museos tradicionales, desconectados de las sociedades a las que se debían. El escrito, titulado Museo Valéry-Proust, identificaba el sinsentido de los museos en las sociedades democráticas contemporáneas, bien por su concepción originaria, bien por las funciones derivadas de esta y que hasta entonces venían desarrollando las instituciones museísticas (Adorno, 2008, pp. 159-169):

La palabra museal tiene en alemán un matiz desagradable. Se refiere a objetos con los que el observador ya no tiene una relación viva y que están muriendo. Estos objetos son conservados más por consideraciones históricas que por necesidad actual. El museo y el mausoleo no están unidos solo por una asociación fonética. Los museos son como panteones de obras de arte. Dan testimonio de la neutralización de la cultura.

Con estas palabras, el teórico alemán identificaba algunos de los aspectos que ponían en jaque a una institución desfasada, anteriormente anticipados por los institucionistas: la reducción de las funciones del museo estrictamente a la conservación de las obras del pasado, la neutralización de la cultura, la pérdida de la relación de las obras con un uso posible, etcétera. Estos hechos problemáticos podrían resumirse en uno: la ausencia de nexos entre los museos y las sociedades que los sustentaban. Pese al ánimo ilustrado con el que se alumbraron los museos en la Europa del siglo XVIII, la naturaleza de las sociedades de ese siglo y de los siguientes terminarían haciendo de estas instituciones espacios semi-privados, reservados para el estudio de los eruditos y el goce estético de las minorías altamente educadas. En este sentido, el mérito de Adorno fue recoger de una forma tan acertada la falta de vinculación de una sociedad futurista -siguiendo la terminología de Pomian- con una institución limitada a la conservación del legado de sus antecesores ad eternum.

Además, Adorno sintetizó en su texto las dos posiciones que representaban en enfrentamiento teórico-práctico surgido en torno al papel del museo. Por un lado, el escritor francés Paul Valéry atacaba al museo desde un punto de vista romántico. 
Para Valéry, el museo era un lugar en el que las obras perdían su efectividad. Como todo romántico, defendía, para el caso de los museos de arte, una concepción nacida de la idea de l'art pour l'art, esto es, el arte por sí mismo: por sus características formales, por su mensaje inherente, por su propia historia y su devenir. El poeta negaba la necesidad de una mediación entre los espectadores y las obras de arte, pues estas serían capaces de expresar su potencial por sus propias características. Este erróneo razonamiento, derivado de una concepción elitista de la cultura, fue el responsable de convertir al museo en un espacio inescrutable, en el que las obras se veían impedidas tanto de expresar su mensaje prístino como de recibir nuevos significados.

Frente a Valéry, su compatriota Marcel Proust defendía justamente lo contrario: que el museo era la oportunidad del arte para dotarse de un nuevo valor. Encarnando el papel de amateur que gracias al museo puede acceder al arte, el autor de Los placeres y los días veía en cada obra algo específicamente estético, pero a la vez otra cosa: «un pedazo de la vida de quien las contempla, un elemento de su propia conciencia (...) una capa que es muy diferente de la capa a la que se refiere la ley formal de las obras» (Adorno, 2008, pp. 165-166). Inconscientemente, Proust estaba anticipando la concepción del museo posmoderno al descubrir un nuevo nicho de potencialidades en el recurso patrimonial, nacidas todas ellas de su despliegue temporal, de su re-significación entre las paredes del museo y su nuevo papel como recurso didáctico al servicio de la ciudadanía. En suma, Proust estaba señalando a la institución centenaria el camino hacia la supervivencia al convertir al museo en un elemento de mediación entre el patrimonio y la sociedad, entre el pasado y el futuro.

Para fortuna de todos aquellos que vemos en los museos auténticos recursos didácticos - sin que eso suponga un menoscabo en su consideración como lugares para el disfrute estético o la investigación especializada-, la crisis analizada por Adorno daría un gran paso hacia su resolución pocos años después. Mayo del 68 supuso una nueva y vigorosa oleada de contestación contracultural que comenzaría a desmantelar los mecanismos de poder que vedaban la cultura para el disfrute de la élite. Lógicamente, se puso también en entredicho "la legitimidad histórica del museo y su derecho mismo a existir, convertido, a los ojos de esta generación, en un anacronismo decadente y dogmático, condenado a muerte» (Bolaños, 2009, p. 21). Fruto de esta revisión del modelo museístico nació en la capital del Sena el centro destinado a marcar el camino a los museos existentes y a los que estaban por venir: el Centro Nacional de Arte y Cultura Georges Pompidou, inaugurado el 31 de enero de 1977. Referente por su arquitectura y por sus propuestas museográficas, el Centre Beaubourg destacó por instaurar una tendencia posmoderna que, con matices, perdura en nuestros días y entiende los museos como "comunidades de aprendizaje (...) que posibilitan múltiples miradas porque reconocen el papel subjetivo de lo expuesto, y en donde la cultura dominante, al quedar desmitificada 
y desestructurada, termina siendo más permeable» (Arias, 2015, p. 138). Así, el museo ha dejado de ser un mero almacén de obras del pasado para convertirse en una «institución permanente, para el bien común, sin fines de lucro y accesible al público, para conservar, estudiar, exponer objetos y especímenes con valor educativo y cultural», según reza la definición del ICOM en su código de deontología profesional (Riviére, 1993, p. 458). El mausoleo del pasado que reprobó Adorno es ahora, según Manuel Castells (2004), una membrana permeable que filtra la relación de la obra con la existencia cotidiana del espacio público, un espacio de cruce de flujos en el que el ciudadano contempla los signos del pasado y del sistema en el que opera. Citando a Stephen E. Weil, Isabel García Fernández incide en el hecho de que los museos de hoy, al igual que las escuelas, no deben ser templos sino laboratorios, lugares «donde la verdad y la belleza se descubren; no mediante la revelación, sino a través de la prueba y el error pacientes (...) Hoy se apuesta por la imagen de foro que incorpora también la de laboratorio, mucho más acorde con la idea contemporánea de la cultura participativa» (García Fernández, 2015, p. 41).

En resumen, los museos han tenido claro su papel cultural como depositarios de conocimiento desde sus orígenes, pero frecuentemente estos conocimientos se han dirigido a un público erudito, nada despreciable (Fernández, 2003). Sin embargo, en el momento en que los museos se comprometieron en ser espacios de instrucción, educación y divulgación orientados a público diverso, se han visto obligados a presentar su patrimonio y a hacerlo comprensible. Esto ha implicado saber transferir todo un conjunto de conocimientos científicos de manera que facilite llenar el saco del bagaje cultural del que todo ciudadano debería poder sacar provecho. En este sentido, Pilar Marco Tello, profesora de la Universidad de Valladolid, defiende que las obras de los museos son excelentes recursos didácticos «para el desarrollo de la sensibilidad, la percepción, el conocimiento, así como la adquisición de diversas actitudes, entre ellas el comportamiento cívico, la apreciación de la diversidad, etcétera» (Marco, 2007, p. 388). Pero no basta con el propósito: para que este potencial educativo se desarrolle, debe darse un fenómeno comunicativo efectivo. De nada sirve hacer del museo una escuela si se mantienen los códigos, mensajes y metodologías que exclusivamente dominan las minorías intelectuales. Puede afirmarse, por tanto, que la cuestión oscila entre mantener el rol del museo como una entidad para el pasado o mutarlo en otra para el futuro; pero incidiéndose en el hecho de que, de optarse por la segunda opción, la reivindicación habría de incluir un ambicioso programa para modernizar los procesos educativos que en él se habrían de desarrollar. Pese a la lógica del razonamiento, la resolución de la primera cuestión a favor de la inclusión de la función educativa entre las propias del museo contrasta con la lentitud con la que se aplica la segunda. En los primeros pasos para la articulación de ese modelo de museo en el que el proceso educativo fuese provechoso e inclusivo desempeñó un papel importantísimo la ILE, aspecto que veremos en los siguientes epígrafes. 


\section{LA ILE Y EL MUSEO. EL PAPEL DE MANUEL BARTOLOMÉ COSSío}

En el proceso de búsqueda de un beneficio compartido entre dos instituciones plenamente humanas y a la vez tan ajenas, jugaría un papel importantísimo la ILE y, muy especialmente, el director del Museo Pedagógico Nacional, Manuel Bartolomé Cossío. En las aulas de la Residencia de Estudiantes, donde practicaron nuevos métodos de enseñar, y fuera de ellas -en los museos, parajes naturales o conjuntos urbanos patrimoniales- los institucionistas procuraban dar a conocer los dos fines capitales atribuidos al patrimonio cultural y, por tanto, al museo: servir para la educación de la sociedad y conservar los materiales con los que se redactan los relatos compartidos. Esta visión del museo como un libro responde al positivismo del que la ILE se empezó a imbuir, madurando sus iniciales postulados krausistas, y tuvo una importante influencia incluso en el Museo del Prado, donde caló la demanda de Cossío de una museografía propia de una galleria progressiva, apta para un mejor entendimiento de la historia del arte (Arnaldo, 2016). Sin embargo, sería en el Museo Pedagógico Nacional donde estos fundamentos alcanzasen mayores cotas, al diseñarse tanto la colección como la presentación de la misma con el propósito de facilitar el estudio de «la ciencia de la educación y su historia, los problemas actuales de la misma, los métodos y la organización comparada de la enseñanza» (Lorenzo, 1999, p. 130).

En este sentido, si bien el papel de Cossío en la renovación de la pedagogía ha sido estudiado con profundidad, no ha ocurrido lo mismo con su faceta como museólogo. Es este un aspecto totalmente meritorio de vindicación por su defensa, a nivel conceptual y práctico, de la noción del museo como un ente que, por medio de la educación y la mediación social, trascendiese sus tradicionales funciones de conservación, contemplación e investigación de lo objetual. Así, las propias palabras pronunciadas por el joven Cossío en Congreso Nacional de Pedagogía de 1882 denotan una honda inquietud por la perpetuación de las desigualdades sociales a través del variante acceso a la educación en función de clase, lugar de residencia u otros factores (Cossío, 1929, p. 215):

El niño de la ciudad tiene, señores, el periódico, el teatro, la conversación culta de la atmósfera que le rodea, los museos, una exposición permanente en los escaparates de cada tienda; pero el pobre niño del campo, ¿dónde puede ver jamás una estatua? ¿Quién le dirá que ha habido un Shakespeare o un Velázquez? ¿Quién le hará sentir la belleza de una melodía de Mozart, de una estrofa de Calderón o un Eco Nacional de Ruiz Aguilera? ¿Quién le excitará a que levante sus ojos de esa tierra que fecunda quizás ya al lado de sus padres? ¿Quién le instará para que piense, reflexione sobre algo que no sea corporal, ni quien le llamará la atención jamás sobre el placer que de la reflexión resulte? 
Como veremos posteriormente, este lamento sería determinante en la configuración de las actividades del Museo, muy especialmente desde la asunción de la dirección de las Misiones Pedagógicas de la II República. Pero, además, la vindicación personalizada por Cossío de la centralidad de la educación en el ámbito del museo le llevaría a defender la inclusión definitiva del proceso educativo como la función primordial del mismo. Es así como confluyen exitosamente en la institución museística pasado, presente y futuro: no solo permitiendo y filtrando la inclusión de retazos del tiempo actual en la colección, como promovían los continuistas, sino haciendo de la colección una herramienta al servicio de la sociedad: «ante todo, el Museo debe ayudar a la formación de educadores siendo centro y exposición permanente y vida del estado de nuestras escuelas (...) para servicio de todas aquellas personas a quienes interese ya profesionalmente ya socialmente» (Otero, 2007, pp. 124-136). Estas palabras confieren a la figura del institucionista plena contemporaneidad, al dotar a su propuesta teórica de un enfoque radicalmente opuesto al entonces vigente, mutando de la preeminencia del pasado sobre el tiempo actual y el futuro al sometimiento de lo pretérito a las necesidades vigentes. Esta concepción emana del convencimiento en el potencial del pasado para modificar el presente, una visión en línea con la transición de un mundo pasadista a uno futurista que estaba aconteciendo en aquel tiempo.

Por otro lado, en el ámbito de las excursiones pedagógicas celebradas por la ILE, 220 según la Memoria de la Junta de Accionistas de 1880 (Molero, 1985, p. 86), Cossío fue precursor en la celebración de al menos dos visitas al Museo del Prado para el ciclo escolar primario de los alumnos de la ILE, programadas con objetivos y metodologías específicos para cada grupo en función de su edad (Arnaldo, 2016). Puede observarse que, contrariamente a lo que opinaba Valéry, Cossío defendía décadas antes el potencial educativo de las obras musealizadas (Cossío, 1884, p. 188):

Los museos de bellas artes se han considerado hasta aquí sólo bajo dos aspectos; o bien como destinados a la contemplación y puro goce estético, o dedicados exclusivamente al aprendizaje especial del artista, pero nunca como centros donde la educación artística, no la particular, sino la general del hombre, tanto bajo el punto de vista de la inteligencia como del sentimiento, debe desenvolverse.

Con estas palabras, Cossío abría el camino a la utilización del museo no solo como recurso didáctico a nivel formal, es decir, como apoyo a los contenidos impartidos en la escuela, la universidad, etcétera; sino muy especialmente a nivel noformal, comprendiendo por tal el proceso educativo desarrollado en instituciones sociales ajenas a la estructura educativa normativa -los museos, entre ellas-; e incluso informal, término en el que se incluyen, entre otros, el autoaprendizaje o la 
socialización entre ciudadanos, hechos que indudablemente se dan en el marco del museo. Esta postura, hoy mayoritariamente asimilada, debe considerarse radical en su contexto histórico, y fue la base para la concepción y el desarrollo del Museo Pedagógico Nacional.

Como acabamos de ver con el caso de las bellas artes, Cossío era un firme defensor de la educación a través de las obras de los museos. Sin embargo, al configurar la idea de un museo pedagógico, basado en una colección de objetos nacidos para educar, encontró que «Los productos del museo no pueden estimarse por sí mismos, sino que valen en cuanto expresión de la actividad educadora, único factor que importa en este caso, contrariamente a lo que ocurre con las obras de arte» (Otero, 2007, p. 134). De esta manera diferenciaba el director del Museo las obras relativas a la ciencia e historia pedagógica de las artísticas en que, a diferencia de las primeras, en las segundas únicamente se pretende la comunicación a través de la belleza, independientemente de que una función educativa les sea asignada a posteriori. Centrando el foco en objetos patrimoniales cuyo valor residía exclusivamente en su función educativa, Cossío pudo afianzar la conclusión que ya sospechaba ante el caso de objetos cuya función no era en origen estrictamente educativa, como era el caso de las obras de arte. El razonamiento consistía en que, si para educar a distintos públicos se pretendían utilizar objetos educativos musealizados, el proceso debería centrarse en el proceso mismo, en cómo sirven para enseñar, pues la educación consiste "en un proceso» (Otero, 2007, p. 134). Con este razonamiento se dota de suma coherencia la conclusión de que la visita al museo debería implicar no a un «utensilio mudo, sino la de su funcionamiento en vivo" (Otero, 2007, pp. 134-135). Llegado a este punto, el director del Museo alcanza la infranqueable paradoja de cómo desarrollar una función dinámica a través de bienes arrancados de su contexto espacio-temporal, "hechos estables -productos, objetos estáticos-» (Otero, 2007, p. 136). El valor de Cossío en este punto está no en resolver la paradoja, sino en invalidar un planteamiento erróneo, el que pretende que sean los objetos - sea cual sea su naturaleza- depositados en los museos, por sí mismos, los que comuniquen sin la intermediación del personal educativo, a quien corresponde la tarea de comunicar y analizar críticamente el material museístico. En suma, el institucionista estaba anticipándose a lo que décadas después afirmaría Adorno (1962, p. 199) en su contestación a la crítica de Valéry al museo: «Valéry es demasiado ingenuo en su sospecha de que el mal es simplemente inferido por los museos a las obras. Las obras aún colgadas en sus viejos lugares, en los palacios de esos aristócratas (...) son piezas de museo sin museo. Lo que roe la vida de la obra de arte es al mismo tiempo su propia vida». Invalidada la paradoja, Cossío se muestra plenamente consciente del nuevo rol del museo en la sociedad y de sus dificultades para desempeñarlo, y a la vez dispuesto a transformar una institución hermética en una herramienta de comunicación y transformación social (Otero, 2007, pp. 135-137): 
Los objetos no hablan sino al que sabe preguntarles y no contestan sino en la medida que se les interroga (...) El Museo Pedagógico no puede existir sin elementos vivos que analicen su contenido: que lo examinen, lo desentrañen, lo critiquen (...) Vivificarlos ¿cómo? Pues con lo que da vida que es el hombre.

Estas tesis tuvieron su aplicación tanto en las visitas escolares al Museo del Prado (Arnaldo, 2016) como en la configuración y devenir del Museo Pedagógico Nacional, y descubrieron un prometedor camino a los museos en su relación con la sociedad y que culminó, en la segunda mitad del siglo XX, con la creación de los Departamentos de Educación y Acción Cultural (DEAC) en los museos, enfocados a la formación de distintos públicos. Con todo, parece que el problema no termina de resolverse, quedando aún en el tintero el reconocimiento profesional del educador del museo (Arnaldo, 2008, p. 21).

Otro aspecto al que se debe dar especial atención a la hora de analizar el papel de Cossío en el diseño y funcionamiento del Museo son los numerosos viajes que realizó por Europa con los objetivos de analizar diferentes museos con el fin de construir un modelo de museo pedagógico coherente y eficaz; conocer los últimos avances en los ámbitos de la pedagogía en los congresos en los que se presentaban al público y de perfeccionar su dominio idiomático, un punto en el que las oposiciones al cargo de director incidían debido a la voluntad de los impulsores del Museo de abrirlo al exterior. Entre el 12 de agosto y el 24 de septiembre de 1882, el futuro director del Museo Pedagógico visitó los museos de París, Berna, Basilea, Zúrich, Múnich, Viena, Praga, Dresde, Berlín, Leipzig, Colonia y Bruselas, tomando notas sobre los museos pedagógicos de estas ciudades. Por citar algunos ejemplos, del Museo de Zúrich indicaba que su personal no recibía honorarios y que organizaba pocas exposiciones, pero destacaba como notas positivas que disponía de un notable número de manuscritos de Pestalozzi en su biblioteca y que publicaba un boletín; del de Berlín que disponía de una buena biblioteca que prestaba sus recursos y que disponía de material relevante para el análisis de la enseñanza, pero que su exposición era reducida; y del de París, que era sustentado por el Estado, que funcionaba como un repositorio de documentos y una oficina de estadísticas y que su biblioteca prestaba documentos a toda Francia, pero no objetos (Otero, 2012, p. 210). Todo este bagaje permitiría a Cossío diseñar una herramienta digna de admiración para los especialistas europeos pese a las dificultades presupuestarias y a las turbulencias políticas.

Por último, debe subrayarse en la figura de Cossío su interés por vincular el Museo Pedagógico con instituciones sociales como la escuela y la universidad. Consciente de la necesidad de mejorar la situación científica y pedagógica de las abandonadas Escuelas Normales en las que se formaban los docentes, el director razonaba que debía establecerse una relación bidireccional entre estas, el museo y la escuela. Las escuelas deberían enviar el material con el que el maestro «prueba e informa su actividad educadora, y el Museo (...) a la escuela los productos obtenidos en su 
laboratorio» (Otero, 2007, p. 125). Asimismo, el museo establecería sistemáticamente lecciones destinadas a los alumnos de las Escuelas Normales, deseando el director que con el tiempo llegasen a ser obligatorias, como era el caso del Museo de Berlín, o que al menos se extendiesen «certificados de asistencia y aprovechamiento al curso, expedidos por el Museo, (...) tenidos en cuenta por el Ministerio» (Otero, 2007, p. 130), una función que hoy en día realizan los museos en nuestro país y de la que el institucionista fue, a tenor de este testimonio, un claro precursor.

\section{EL MUSEO, LEGITIMADOR DE LA CIENCIA PEDAGóGICA}

Hemos visto anteriormente que los intelectuales españoles afines al krausismo veían en la educación la herramienta destinada a renovar España a través de la formación de ciudadanos más educados y, por tanto, más iguales en oportunidades. Este hecho confería a la pedagogía una importancia inaudita en nuestro país, frente a una serie de poderes fácticos radicalmente opuestos a los objetivos de los reformistas, y por extensión, a los postulados de la ciencia pedagógica. Valgan a modo de ilustración de este hecho tres referencias. La primera, la introducción del texto de Krause El ideal de la humanidad para la vida, libro de cabecera de la mayoría de los reformadores liberales traducido por Sanz del Río, en el Índice de Libros Prohibidos de la Iglesia (Molero, 1985, p. 20). La segunda, la carta que envía a Cossío Ricardo Rubio (Figura 3), alumno de Giner de Los Ríos y secretario del Museo Pedagógico Nacional, a tenor de la Asamblea General de Enseñanza y Educación convocada en 1910 por Julio Burrell, sustituto de Romanones en el Ministerio de Instrucción Pública, con el fin de tratar las reformas que el sistema educativo español precisaba: «ya se nos quitó la preocupación de la Asamblea General de Enseñanza. Parece ser que la suspenden asustados de la avalancha clerical formidable que se les venía encima» (Arias y López, 2014, p. 753). Rubio hace referencia a la reacción de los ultracatólicos, quienes, respaldados por periódicos y agrupaciones reaccionarias como El Universo y la Asociación Benéfica de la Enseñanza Católica, «que proponía, de entrada, la prohibición de toda escuela que no fuese católica» (JiménezLandi, 1996, p. 22), se inscribieron masivamente a la Asamblea con el fin de influir en sus posicionamientos finales. El tercer documento que permite visualizar la situación de la educación española es la carta de un maestro publicada en el periódico La Acción del 9 de junio de 1918 («Carta de un maestro», 1918, p. 3):

Mientras tanto, aquí en Madrid gasta el Estado 52.000 pesetas anuales en sostener el Museo Pedagógico Nacional, que no sirve para nada, es decir, que sirve solo para justificar unos cuantos sueldos de otros tantos paniaguados de la Institución Libre de Enseñanza. Sería curiosa una encuesta entre todos los maestros de España acerca de la utilidad de este Museo, cuya biblioteca pública debería estar a cargo del Cuerpo de Archiveros Bibliotecarios. 


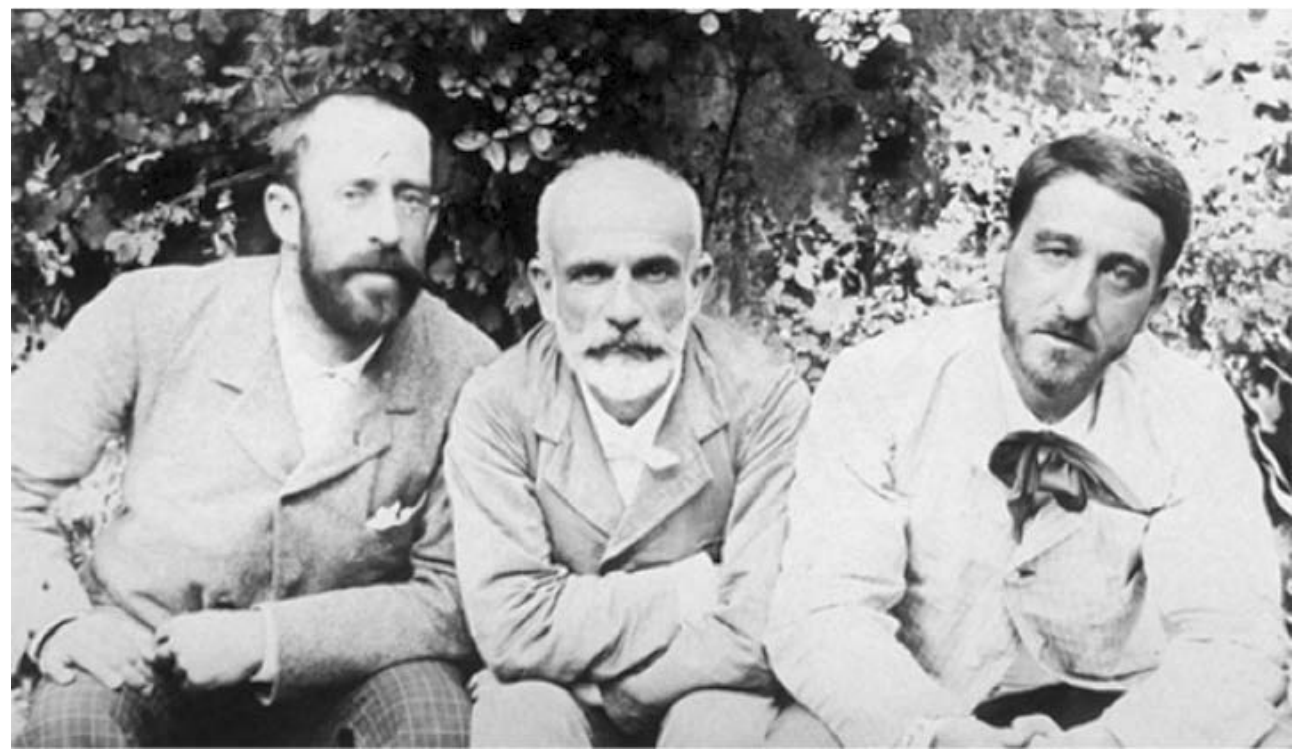

Figura 3. Ricardo Rubio, Francisco Giner de Los Ríos y Manuel Bartolomé Cossío.

Este testimonio, treintaiséis años posterior a la fundación del Museo, es esclarecedor tanto del estado en el que se encontraba el reconocimiento de la pedagogía en aquel tiempo, como de los temores que planteaba una renovación educativa a gran escala. La situación española debía ser similar a la de otros regímenes occidentales, evidenciándose, ante la adversidad del ambiente, la necesidad de que la ciencia de la educación se dotase de un espacio social que materializara su discurso.

La pregunta que nos aborda ahora es ¿por qué debía ser el museo, y no otra institución, quien se erigiese en motor de progreso a través de la mejora de la educación? La respuesta enlaza con las corrientes filosóficas de las que la ILE fue deudora, pero también con papel histórico de los museos en las sociedades humanas. Sabemos que, desde sus orígenes, el museo es un espacio en el que se forjan y legitiman relatos a través de la visibilidad de los objetos expuestos. Sabemos, asimismo, que el museo de la segunda mitad del siglo XIX es hijo del positivismo, corriente de pensamiento que los miembros de la ILE habían incorporado progresivamente a sus iniciales posicionamientos krausistas (Abellán, 1989: 405). Así, los institucionistas encontrarían en el museo la herramienta perfecta para legitimar sus postulados, una estrategia similar a la que desarrollaría el Nature History Museum de Londres con la rebatida $-y$ ridiculizada- teoría de la selección natural de Charles Darwin en un proceso que incluyó la colocación de una estatua del naturalista en el hall del Museo británico en 1885 (Figura 4). 


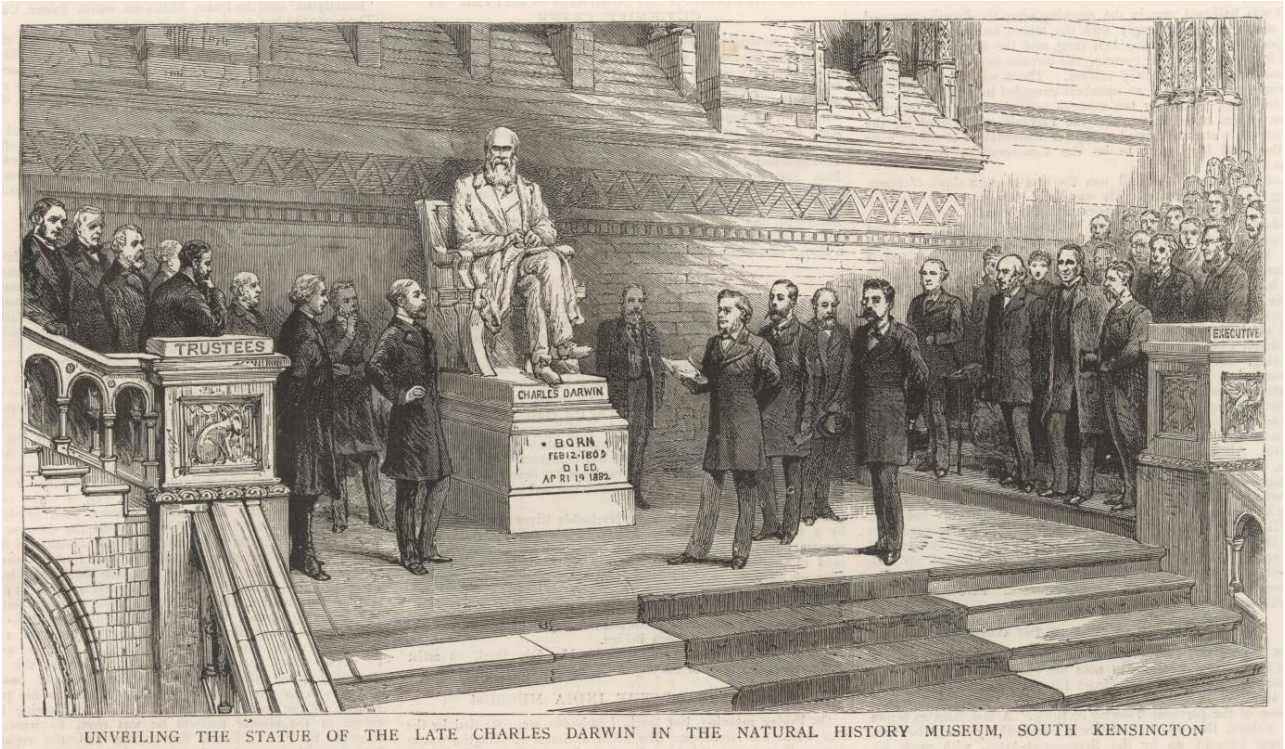

Figura 4. Unveiling the statue of the late Charles Darwin in the Natural History Museum, South Kensington. The Graphic, 20 de junio de 1885. La estatua fue tallada por el insigne escultor Sir Joseph Edgar Boehm (1834-90).

En suma, la tarea de Cossío y sus compañeros consistiría en adaptar el ejemplo de otros países al contexto propio, tomando de aquellos lo que se consideraba acertado para la consecución de sus objetivos. A través de la colección y sus profesionales, el Museo materializaría un relato histórico-científico ordenado de la cuestionada pedagogía, consiguiendo así imbuirle de una fuerte legitimidad social. Influenciado, al igual que sus compañeros de la ILE, por las teorías positivistas, Cossío va a proponer un museo que instituya un discurso ordenado, representativo, científico, de la ciencia pedagógica. Así, el catálogo del Museo es claro en sus intenciones: construir «un conjunto con sentido orgánico, formado y distribuido conforme al principio mismo de la ciencia de la educación y la naturaleza del material de enseñanza, objeto fundamental del Museo» (García del Dujo, 1985, p. 123). En resumen, la colección de objetos debería ordenarse "en secciones ordenadas» (Cossío y Otero, 2007, p. 129) que atendiesen a las principales problemáticas que trataba la ciencia pedagógica.

Por este motivo, los objetos de la colección del Museo, procedentes en la mayoría de los casos de la exposición pedagógica celebrada en Madrid en junio de 1882 con motivo del Congreso Nacional de Pedagogía de ese mismo año - «Material científico de estas enseñanzas; colecciones de objetos empleados en las lecciones de cosas...» (García del Dujo, 1985, p. 52)-, se ordenaron con el afán de visualizar el corpus teórico de la pedagogía a través de sus medios. En sus testimonios, Cossío evidencia su afán por clasificar lo expuesto: por un lado, 
todo lo referente a los medios que «sirven directamente para la educación y la enseñanza" y por otro, los que "prestan su concurso para que se desarrollen éstas en buenas condiciones» (Otero, 2007, p. 128). Del primer grupo deben destacarse los métodos pedagógicos, los instrumentos, las colecciones y la propia biblioteca, que debería incluir todo tipo de materiales de enseñanza. En el segundo, Cossío incluye planos y modelos de centro educativos, "de la distribución más conveniente del solar, de la forma general de los edificios, de sus dimensiones, de su orientación y emplazamiento, de los diversos sistemas de ventilación y calefacción» e incluso la decoración de las fachadas y partes exteriores (Otero, 2007, p. 129).

Lo extenso de esta descripción podría llevarnos a atribuir un fetichismo objetual a Cossío y sus compañeros. Sin embargo, también en este aspecto los responsables del Museo fueron fieles a la modernidad, advirtiendo el riesgo de concentrar la preocupación totalmente en los medios materiales de enseñanza (García del Dujo, 1985, p. 120). Por este motivo, el Museo debería reducir dicha preocupación estrictamente a lo relativo a construcción y mobiliario escolar, siempre a la luz de los principios establecidos en los congresos pedagógicos. En este sentido, el Real Decreto de 6 de mayo de 1882 recoge la filosofía originaria de otros centros pedagógicos y define el centro como un espacio de reunión y exposición de «libros, planos, dibujos, proyectos de edificios, mobiliario y menaje, material de enseñanza y cuantos objetos, en suma, tienen relación con el estudio, la higiene y los progresos de las escuelas públicas», alrededor de la cual se organizarán otras actividades complementarias. Atendiendo a la museografía, podemos afirmar que la voluntad de construir un museo que desarrollase correctamente su función educativa, materializada en base a la experiencia pedagógica atesorada por la ILE, permitió superar por medio de su museografía el modelo de museo-vitrina. Respecto de la misma, el decreto fundacional indica que "la instalación de los diversos objetos del Museo se hará de modo que pueda servir para dar a conocer el estado de la primera enseñanza en España, así como de las demás naciones, y para facilitar a la vez el estudio y planteamiento de los adelantos que ofrece el progreso de la Pedagogía» (García del Dujo, 121).

Para concluir este apartado, debe incidirse una vez más en la influencia positivista que orientó las acciones de los profesionales del Museo, quienes advierten en el primer catálogo, concluido en 1890, que «la idea de la organización del contenido del Museo supone el desarrollo íntegro de la ciencia de la educación» (García del Dujo, 1985, p. 122). Un influjo que ya se percibía en las propuestas de Cossío para la compleción de la colección del Prado (Arnaldo, 2016) y ahora al defender que los profesionales del Museo viajasen por España y otros países con el fin de reflejar fielmente "el estado de nuestras escuelas y de las del extranjero» (Otero, 2007, p. 130). 


\section{LA ACCIÓN EDUCATIVA, LEGITIMADORA DEL MUSEO}

Anteriormente vimos que, en 1923, Valéry vislumbraba en la acción educativa del museo un síntoma de la decadencia de la cultura. Frente a este planteamiento, las propuestas de los institucionistas, enunciadas años antes, se encontraban en el punto opuesto: la legitimación del museo nacía de su impacto en la sociedad a través de proyectos educativos, científicos y de mediación social de diversa índole. En otras palabras, el museo debía existir para "poner a prueba el estatuto del ciudadano, ejercer una crítica permanente del presente» (Arnaldo, 2013, p. 83). El museo debía ser, por tanto, una herramienta para la educación, para el progreso en igualdad.

En este sentido, la tarea de mediación entre la ciencia y la sociedad que desarrolló el Museo Pedagógico Nacional, ejecutada a través de proyectos y actividades derivadas de la investigación científica y protegidas por la libertad de cátedra, encuentra su justificación en el ideario krausista. De esta manera, el Museo se erige como el primer caso en nuestro país en el que conservación y educación van de la mano. El museo sigue siendo un guardián del pasado, sí, pero que encuentra su justificación en el presente, al definirse como una lanzadera hacia el futuro: una herramienta de progreso social a través de la educación. En este campo, la concepción del Museo Pedagógico incide en aspectos que, hoy en día, consideramos indispensables en un museo: acción educativa, investigación científica, enfoque a públicos diversos y proyección en el territorio. Una vez más, las aseveraciones de Cossío vuelven a ser esclarecedoras: «museo pedagógico que sea una mera exposición de material es un museo muerto; y su utilidad, muy dudosa» (Otero, 2007, p. 134). Asimismo, en referencia al catálogo de la colección afirmaba que este no debía restringirse a una mera información del nombre y la naturaleza del objeto, sino que tenía que tratar detalles fundamentales que le diesen «un interés más vivo» (Otero, 2007, p. 131): ilustraciones $y$, muy especialmente, juicios críticos de los objetos y metodologías educativas, redactados por los profesionales del museo.

Anteriormente hemos tratado los principios estatutarios que dirigieron la elaboración de la colección del Museo y su museografía. Sin embargo, al igual que en el caso anterior, la norma recogió la función del museo en relación con la educación. En este sentido, Cossío defendía que el museo estaba llamado a la educación de los maestros, antes que a la de los niños (García del Dujo, 1985, p. 53), si bien manifestó repetidamente en sus testimonios que el Museo debía ser accesible para todo ciudadano interesado en sus colecciones y actividades. Este es uno de los puntos cardinales en la propuesta museográfica de Cossío. En dos cartas fechadas el 26 de noviembre y el 1 de diciembre de 1910, Ricardo Rubio, secretario del Museo, le informaba de las lecciones que se habían impartido en fechas recientes y de las gestiones que se estaban llevando a cabo para celebrar un breve curso de física consistente en una decena de lecciones relativas al calor, el sonido, la electricidad, etcétera, absolutamente experimentales y con un público infantil limitado (Arias y López, 2014, p. 753). El desarrollo de estas actividades 
encuentra su origen en el propio director del Museo, quien, como hemos indicado anteriormente, ya en la década de los ochenta del siglo anterior había organizado varias visitas al Museo del Prado con grupos de estudiantes de distintas edades, iniciativa que creó, a la postre, un incipiente estado de opinión favorable a la apertura social de los museos en algunos círculos intelectuales. Destaca, en este sentido, el caso de Aureliano de Beruete y Moret -alumno de Cossío y participante en las visitas-, director de la pinacoteca madrileña entre 1918 y 1922, por impulsar la labor docente en las estancias del Museo al facilitar que se extendiese "gratuitamente un billete» a "los maestros y directores de los establecimientos de enseñanza» y a sus alumnos en el reglamento de 1920 (Arnaldo, 2016).

Otro de los aspectos que evidencian el fuerte vínculo establecido entre las tradicionales funciones del museo y la educación en el Museo Pedagógico Nacional fue su biblioteca: el Museo se dotó, a lo largo de su vida, de una ingente compilación de documentos - llego a ser la segunda del Estado en número de lectores tras la Biblioteca Nacional (García del Dujo, 1985, p. 129) y la primera en fondo editorial (Molero, 1985, p. 127)-. La biblioteca se erigió siguiendo el modelo francés, al que añadió algunas funciones de gran valor, entre las que puede citarse el préstamo de objetos, a diferencia de su hermano galo, que exclusivamente prestaba material bibliográfico. Además, el Museo asumió, en la década de 1920, la gestión de la Biblioteca Circulante para Niños, un fondo móvil compuesto por casi 3.800 volúmenes entre los que se encontraban tanto libros de literatura infantil como textos escolares para el aprendizaje -en el ámbito de la instrucción primaria- de la lectura, la escritura y el cálculo: cartillas, gramáticas, lecciones sobre la naturaleza, lecturas sobre personajes históricos, viajes, cuentos y normas de urbanidad. Esto recursos, sumados a la programación de todo tipo de actividades educativas en las instalaciones de Museo y la exposición de materiales pedagógicos del presente de España y de otros países, intentaba solventar los problemas de la educación española y así, legitimar, por medio de la crítica y la acción educativa, la manutención del pasado. Lo cierto es que, en este ámbito, Cossío se muestra sumamente moderno en sus planteamientos. El institucionista no se limitó a sumarse a una corriente contemporánea que se materializaba en los museos industriales y en las exposiciones internacionales -el hecho de que la Exposición Universal de Chicago de 1893 incluyese en el Pabellón de Bellas Artes una vitrina en homenaje a Pestalozzi (Blanco, 2005, p. 133) es bastante representativo-, donde se exhibían maquetas, planos, materiales de enseñanza, etcétera, sino que también criticó el fetichismo del objeto que, consideraba, atenazaba a estas instituciones.

Afirma María Bolaños a tenor de los orígenes de los museos de la industria que fueron considerados auténticos «institutos del progreso» (Bolaños, 2008, p. 282) ya desde el nacimiento de la idea, que arrancó en la Francia revolucionaria con el Conservatoire des Arts et Métiers en 1794 y que se extendió por Europa generando ejemplos que, si bien no se concebían como museos, se caracterizaban por asumir y actualizar las tradicionales funciones de estos desde un ánimo vanguardista (Bolaños, 
2008: 283). Ya en el siglo XIX, el liberal Ruiz Zorrilla, ministro de Fomento de Amadeo I de Saboya, firmará un decreto «ordenando la creación de un museo industrial asociado a los estudios de artes y oficios». Este proyecto, inspirado en ejemplos como el South Kensington Museum -fundado en 1852 y que posteriormente pasaría a denominarse Victoria \& Albert Museum- y muy especialmente el Musée de l'Industrie de Bruxelles, once años anterior al caso británico, promovía la exposición de técnicas y productos del pasado con el fin de fomentar la formación de amplias capas sociales «en los nuevos adelantos de la ingeniería y de la industria» (Bolaños, 2002, p. 287) y el aprendizaje directo de las técnicas del pasado para su aplicación presente y futura, evitando así su extinción (Figura 5). El proyecto no llegaría a materializarse hasta 1912, bajo el nombre de Museo de Artes Decorativas, en el que se recogía (Bolaños, 2002, p. 288)

el doble estatuto, testimonial y renovador, de los objetos expuestos, pues en sus fondos se incluían obras de arte únicas, testigo de procedimientos técnicos ya irrecuperables (...) frente a objetos desconocidos, destinados a fecundar la imaginación de los modernos obreros: se proponía como el motor de una poderosa corriente de modernización de las industrias (...) Este fin educativo habría de materializarse en conferencias y cursos públicos, colecciones circulantes, catálogos de bajo precio, concursos nacionales y una biblioteca especializada con libros, revistas, estampas y fotografías.

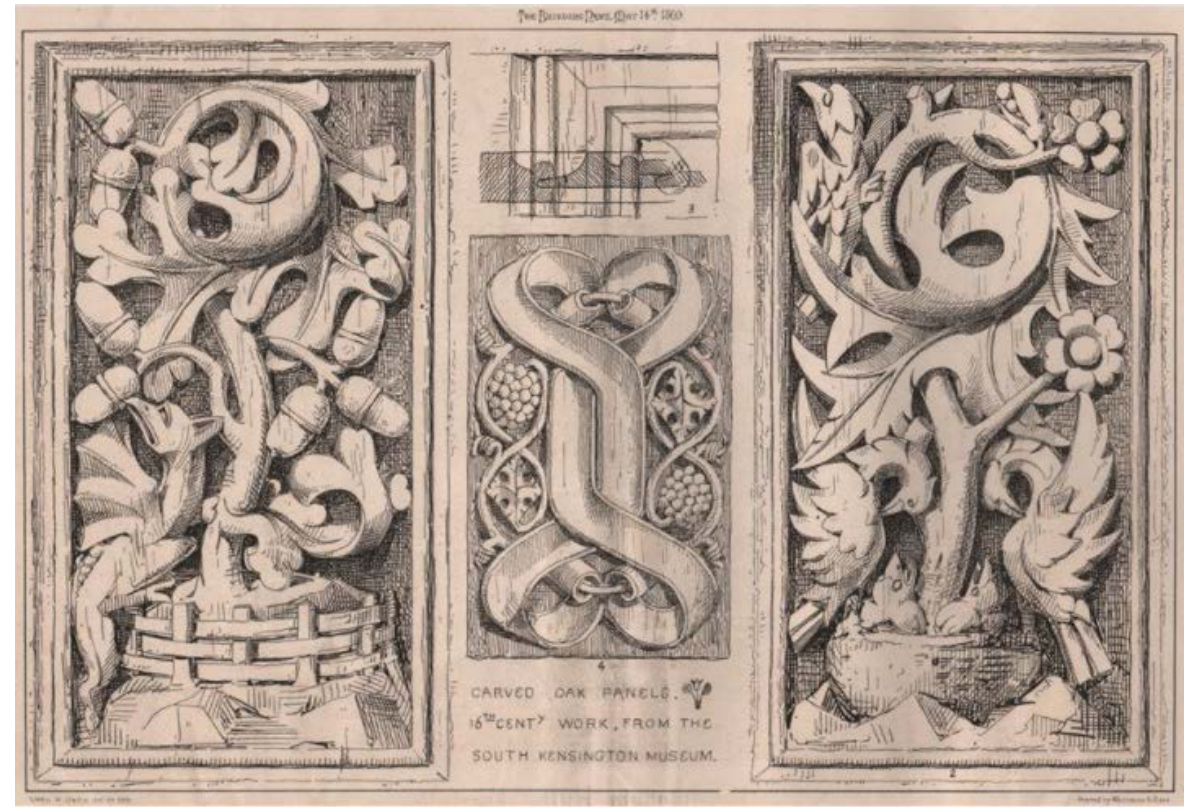

Figura 5. Carved oak panels. 16th Centy work, from the South Kensington Museum. The Building News, 14 de mayo de 1869. Dibujo y litrografía de Owen W. Davis, impresa por Whiteman \& Bass. Modelo para un panel de madera tallada, inspirado en las colecciones del museo. 
Esta descripción de la misión y métodos del museo es, como trataremos a continuación, prácticamente idéntica a la que definió el Museo Pedagógico Nacional, fundado treinta años antes que el de Artes Decorativas. ¿Cómo, entonces, hizo suya Cossío esta nueva idea de museo? La respuesta se encuentra en los viajes que realizó antes de conseguir el puesto de director del Museo, ya citados, pero también en los realizados después: en 1884 asistió con Giner a la Conferencia de Educación celebrada en South Kensington, donde apreciaron los progresos que se venían realizando en este ámbito por el Museo y se empaparon de las innovaciones pedagógicas europeas. Años después, Cossío continuó sus visitas a numerosas instituciones museísticas y educativas que consideraba de interés para el desarrollo del Museo Pedagógico. En una carta enviada a Francisco Giner de Los Ríos desde Hamburgo el 21 de agosto de 1909, indica que su Museo Industrial le pareció «maravilloso» (Arias y López, 2014, p. 344), y gracias a la conservación de otra misiva enviada a Giner el 4 de septiembre de ese mismo año puede constatarse igualmente su visita al Politechnik de Zúrich (Arias y López, 2014, p. 352), actual Escuela Politécnica Federal, famosa en su momento por sus novísimos laboratorios y por perseguir el equilibrio entre la enseñanza teórica y práctica a través de los planes formativos.

Llegados a este punto, debe incidirse en el hecho de que, si bien la función educativa del Museo incluyó conferencias, lecciones y demostraciones prácticas en el seno del museo, esta también se implementaba más allá de sus muros. En este sentido, el Museo desarrollaba una tarea de mejorar la docencia en las anteriormente citadas Escuelas Normales -todavía sin consolidar por la indiferencia de los poderes públicos- y para profesiones como la medicina, la ingeniería o la arquitectura, entre otras (Molero, 1985, p. 125). Así, el Museo Pedagógico Nacional fue uno de los primeros ejemplos de cooperación entre el ámbito museístico y el científico-universitario, al menos hasta la creación de la Junta de Ampliación de Estudios en 1907, cuando esta institución comenzó a capitalizar estas actividades.

Otros dos programas que trascendieron los muros del Museo y de gran interés por su anticipación a las prácticas museísticas actuales fueron, en primer lugar, la creación de escuelas de ensayo y reforma, verdaderas experiencias piloto que consistían en centros ordinarios a los que se concedía autonomía para la realización de sus trabajos bajo la dirección de un patronato, siempre con la orientación y apoyo del Museo (Molero, 1985, p. 126); y en segundo, el amplio movimiento de las Colonias Escolares, promovido especialmente por el Museo. Entre 1887 y 1926, el Museo organizó cincuenta y cinco colonias (García del Dujo, 1985, p. 143) en las que se atendían la rehabilitación de los niños débiles y su integración en la realidad educadora. El aspecto instructivo se cultivaba con las sesiones de lectura, la observación del patrimonio histórico-artístico y natural circundante y con la redacción del diario que cada alumno debía llevar a cabo. Debe destacarse asimismo que, en el contexto de estas colonias no se impartían clases formales 
-anticipando un debate que goza de plena actualidad en el debate educativo-, pero los niños aprendían a percibir y analizar la realidad con sus propios medios, un aspecto que Cossío consideraba de radical importancia por permitirles «expresar sus impresiones mejor que en aquellas» (Molero, 1985, p. 126). Para concluir este punto, debe mencionarse que fueron las limitaciones económicas las responsables de que, en 1926, se cancelasen las colonias en pleno auge de su funcionamiento. El Museo tendría que esperar a 1931 para retomar la iniciativa, al asumir la dirección de las Misiones Pedagógicas de la II República.

\section{UNA NUEVA ORGANIZACIÓN PARA UNA INSTITUCIÓN RENOVADA}

Anteriormente hemos visto cómo la influencia de otros museos pedagógicos en la configuración del Museo Pedagógico Nacional fue muy destacable, si bien Cossío había analizado, gracias a sus viajes, los aspectos que convenían para el museo que planteaba. En este sentido, se ha resaltado la influencia del Museo Pedagógico de París en los estatutos (García del Dujo, 1985, p. 52), pero Cossío había advertido tras su visita al mismo la escasa autonomía de los profesionales de este museo, al igual que su insuficiente preparación en el ámbito de la pedagogía, que atribuía a su exclusiva formación como conservadores, cuerpo funcionarial al que pertenecían no solo los técnicos del Museo francés, sino también su cuerpo director. Afirmaba, a este respecto, Cossío: «El director suele ser un mero conservador sin iniciativa, y la verdadera dirección, alejada del Museo, es (...) intermitente y carece de energía (...) Poner un conserje o un conservador, no sirve para nada. Así París» (Otero, 2007, pp. 136-137). El institucionista anticipaba, así, la revolución que habría de acontecer en el estatuto del conservador, una figura social cuya función permanecía prácticamente inalterada desde la Antigüedad, cuando Cornelio Neponte, contemporáneo de Cicerón, la describió con los términos Conservare summa religione simulacra, conservar con un cuidado escrupuloso las imágenes de los dioses. En este sentido, Jean Clair (2010, p. 11), siguiendo lo aseverado por Krzysztof Pomian en Collectioneurs, amateurs et curieux, afirma en relación a los cambios en la figura del conservador:

«El conservador es aquel individuo que, por delegación de una autoridad superior (...) custodia los tesoros que se le han confiado y que, tanto por su realidad material como por el lugar y el modo en que son expuestos, apartados del circuito económico, atestiguan la identidad, antaño cultual y hoy cultural, del mundo al que pertenecen. Pero en las sociedades contemporáneas el conservador se ha convertido en mucho más que eso. Más que el poder de conservar, tiene el de distinguir las imágenes (...) mediante las cuales el ciudadano reconoce su pertenencia a la comunidad. Ya no solo cuestiona: también mira». 
Así, la idea de que los conservadores debían dirigir la vida del museo, era -y sigue siendo- incuestionable, pero su función empezaba a diversificarse, no limitándose al embalsamamiento de los restos fulgurosos del pasado, sino también al desempeño de una serie de funciones antes inimaginables: un decreto francés de 1910 asignaba a los conservadores las funciones de "conservación, clasificación y mantenimiento de las colecciones, de las investigaciones y negociaciones relativas a su enriquecimiento, de la redacción de los catálogos», pero también de, «mediante un servicio permanente, y mientras los museos permanecen abiertos, las relaciones con el público» (Bolaños, 2002, p. 52). En España, el decreto de 1901 que regulaba la actividad de los conservadores de museos hacía propias las reclamaciones de Cossío y sus compañeros, al asignar a los profesionales de los museos las funciones tradicionalmente atribuidas al cargo y añadiendo otras de total pertinencia en el ámbito que venimos estudiando (Bolaños, 2002, p. 52):

propagar las aficiones a los estudios (...) organizar series o cursos de conferencias prácticas que sirvan para difundir los conocimientos (...) ponerse en mutua correspondencia científica con otros museos y establecimientos docentes nacionales y extranjeros, a fin de obtener el cambio de noticias, antecedentes, publicaciones, fotografías, reproducciones, etc.

Todas ellas son, como venimos viendo, posturas defendidas por Cossío, precursor de la mutación del conceptodel conservadordelatradicióngala haciaeldel conservadoreducador desde la redacción del reglamento del Museo, publicado el 26 de agosto de 1882. En este se estableció que los puestos de las tres secciones que canalizaban la actividad del Museo - material, didáctica e instituciones complementarias- se debían cubrir por concurso-oposición entre maestros, inspectores, profesores y catedráticos. Asimismo, la configuración del personal -director, subdirector, secretarios primero y segundo- y su asimilación para todos los efectos al profesorado de las Escuelas Normales preservaba la autonomía del centro, un aspecto problemático que Cossío detectaría pocos días después en su viaje por Europa. También con el fin de reforzar la independencia del Museo, el Real Decreto de 6 de mayo de 1882 estableció que el Museo dependería directamente de la Dirección General de Instrucción Pública, y programó la creación de museos pedagógicos provinciales que, en relación con el central, aplicasen los avances pedagógicos en cada zona.

Un último punto que debemos tratar en la influencia de la ILE en las políticas de gestión museística es el estudio de públicos, un aspecto en el que el Museo Pedagógico fue, una vez más, pionero en nuestro país. Hemos visto anteriormente que Cossío defendió la oportunidad de que el Museo se dirigiese a un público concreto, el de los maestros -y en menor medida, el de los alumnos-, y no a uno genérico, si bien todo ciudadano debería ser siempre convenientemente informado en caso de manifestar su interés por los contenidos y actividades del Museo. Por 
este motivo, el Museo Pedagógico Nacional orientó su colección, sus exposiciones, sus catálogos, a los protagonistas de la enseñanza, pero acogía también entre sus muros $-\mathrm{y}$ fuera de ellos, a través de su relación con las escuelas, las colonias de verano, las Misiones Pedagógicas, la Biblioteca Circulante y el Museo del Pueblo-a todos los que pudiesen sentirse beneficiados por su ámbito de acción.

\section{EL MUSEO COMO PLATAFORMA INCLUSIVA DE PROMOCIÓN SOCIAL: LAS EXPOSICIONES DE BORDADOS DE 1913 Y 1915}

Afirmaba Cossío que, a la hora de acometer la labor educativa en el Museo, no importaba «que el material sea pobre o rico, viejo o nuevo sino poner al educador en condiciones suficientes para aprovecharlo» (García del Dujo, 1985, p. 134). Esta postura, que aún hoy genera opiniones encontradas, pudo materializarse por tratarse de un material que, ya hemos mencionado anteriormente, no tenía en la belleza o en la excepcionalidad su hecho diferencial -en contraste con las obras de arte o arqueológicas-, sino en su aplicación práctica, derivada del motivo que impulsó su creación: la enseñanza. Por tanto, y pese a no ser extrapolable el ejemplo a los museos de arte histórico de bellas artes, debe reconocerse lo valiente del planteamiento en un momento en el que incluso los museos industriales y los pedagógicos se encontraban inmersos en una vorágine fetichista que algunos teóricos han vinculado con Pestalozzi (Otero, 1994, p. 252) y que situaba en el centro del debate las cualidades de los objetos, y no su aplicación en la vida.

De esta posición intelectual se comprende que, para Cossío, un museo de la educación que pretendiese enseñar a través de sus exposiciones, no podía limitar sus medios a los objetos excepcionales del pasado: debía mantener una constante relación con otros países con el fin de obtener el envío de publicaciones y de materiales que poseyesen en sus depósitos, y con las casas editoriales e industriales del ámbito de la enseñanza, invitándolas a «exponer sus productos en el Museo como medio de propaganda» (Otero, 2007, p. 129). Lo polisémico de esta última palabra exige, sin embargo, aclarar que la postura de Cossío no reducía el museo a una suerte de espacio ferial, sino que lo convertía en examinador de los nuevos medios que sobre la educación se planteasen desde los citados sectores económicos: a tenor de cada objeto expuesto, los profesionales del Museo expondrían una crítica del mismo, publicada además en el boletín del centro. Además, la colección se acrecentaría con objetos adquiridos tras su presentación en concursos establecidos para estimular la construcción de material escolar por los maestros (Otero, 2007, p. 130), estableciendo un nuevo vector entre ambas instituciones.

Por su interés, derivado del hecho de aunar varios de los puntos tratados hasta ahora, debe tratarse un último hito en la historia del Museo Pedagógico Nacional: la inclusión de una donación de bordados en la colección del mismo. Este legado 
tuvo varios benefactores, entre los que destacan Emilia Pardo-Bazán y Emilia Gayangos, esposa de Juan Facundo Riaño, director general de Instrucción Pública en los años en los que se fundó el Museo Pedagógico y, posteriormente, del Museo de Reproducciones Artísticas, tan vinculado con estos bienes y heredero de algunas de las reformas instituidas en el ámbito de la museología por Cossío.

Con este legado, el Museo contribuyó a la revalorización de bordados, telas y otros objetos de artesanía popular que, conviene recordar, eran -y siguen siendo en su inmensa mayoría- de factura femenina. La postura de los miembros de la ILE ante el problema histórico de desigualdad de la mujer ha sido tratada en la literatura científica con cierta profundidad, destacando el papel de Gumersindo de Azcárate (Hernández, 1987, p. 616), si bien no se ha dado la importancia de este hecho en la historia de la museología española. Afirma Elvira Ontañón, (VV. AA., 1985, p. 13) que «el fin de esta colección de bordados, que llegó a ser realmente valiosa, era que las futuras maestras aprendiesen a conocer y valorar los tesoros del arte popular, especialmente el español, y lo transmitieran después en las escuelas». Debemos incidir en el hecho de que Giner, Cossío y el resto de institucionistas defendían el valor de estas obras en la educación por su carga estética-afirmaba Giner que «el arte de lo bello depura al sentimiento, ordena y disciplina la fantasía (...) devuelve en nosotros un sentido ideal que sabe hallar mundos y regueros de luz aún allí donde el vulgo tropieza entre tinieblas» (Bolaños, 2008, p. 343)-, a la que ahora se sumaba, de forma efectiva, su potencial educativo a través de la formación de las maestras y, por tanto, del alumnado de estas. En otras palabras: el papel del museo era, sí, conservar el patrimonio, pero con los objetivos finales de orientar los sentidos y el intelecto individual, de mediar en la relación de las distintas capas de la sociedad con la realidad a través del tiempo pasado, actual y venidero. Para resaltar aún más la gran importancia de este hecho, debe destacarse que la acción del Museo en este campo no se limitó al ámbito expositivo intramuros, sino que trascendió los límites físicos del museo, extendiendo su influencia tanto a lo largo de la geografía como de la estructura socioeconómica española. En este sentido, afirma Antonio Jiménez-Landi (1984, p. 107) a tenor de las excursiones organizadas por la ILE a partir de 1883 que

El excursionismo aún tenía otro aspecto cultural: recoger, en cada pueblo, los productos de su artesanía, el dato de sus costumbres, las canciones propias, los romances viejos... En una excursión institucionista se sugirió a las mujeres de Lagartera que se lanzaran a vender sus bordados fuera del pueblo, y este fue el origen de la venta ambulante que las lagarteranas han desarrollado, después, vestidas con sus trajes típicos. Esta labor de recogida, realizada por la Instituciyn, dio lugar a la Exposición de bordados españoles, que organizó, al correr del tiempo, el Museo Pedagógico Nacional, exposición que había de repetir la Sociedad Española de Amigos del Arte, años después, 
promocionando, así, el estudio de nuestras artes populares, ya recogidas, hoy, en Colecciones y Museos.

Por fortuna, se conservan documentos que nos permiten acercarnos a los planteamientos de estas exposiciones. De la segunda, celebrada en los locales de la Biblioteca Nacional en 1915, se conserva el catálogo de la exposición. La consulta del mismo muestra que incluyó numerosas obras de los siglos XVI al XIX, cuatro de ellas pertenecientes al Museo Pedagógico Nacional (Valverde, 1915). Por su parte, de la primera, celebrada en 1913, disponemos de una reseña en la gaceta de pintores y escultores Por el Arte. En ella se informa de que la exposición, «celebrada en los salones altos de la casa Lisárraga sobrinos, [fue] entre las muchas que se han celebrado en el mes de mayo (...) la que más vivo interés ha despertado en el público» (Anónimo, 1913, p. 1). Asimismo, queda recogido que fue organizada «por el concurso del Museo Pedagógico Nacional y de algunos generosos coleccionistas» (Anónimo, 1913, p. 3) y que en ella se exhibieron obras españolas y extranjeras, principalmente de los siglos XVIII y XIX, junto con algunas anteriores a ese período (Figuras 6 y 7) y «Bordados hechos en la actualidad, sirviendo a nuevas aplicaciones, bajo la inspiración de los populares, por influjo del Museo Pedagógico Nacional y con objeto de propagar los buenos modelos tradicionales y de fomentar en esta dirección el trabajo de la mujer» (Anónimo, 1913, p. 9). Rompía el Museo, así, una vez más las fronteras entre pasado, presente y futuro, tal y como ya había hecho en la configuración, presentación y exposición de sus colecciones.
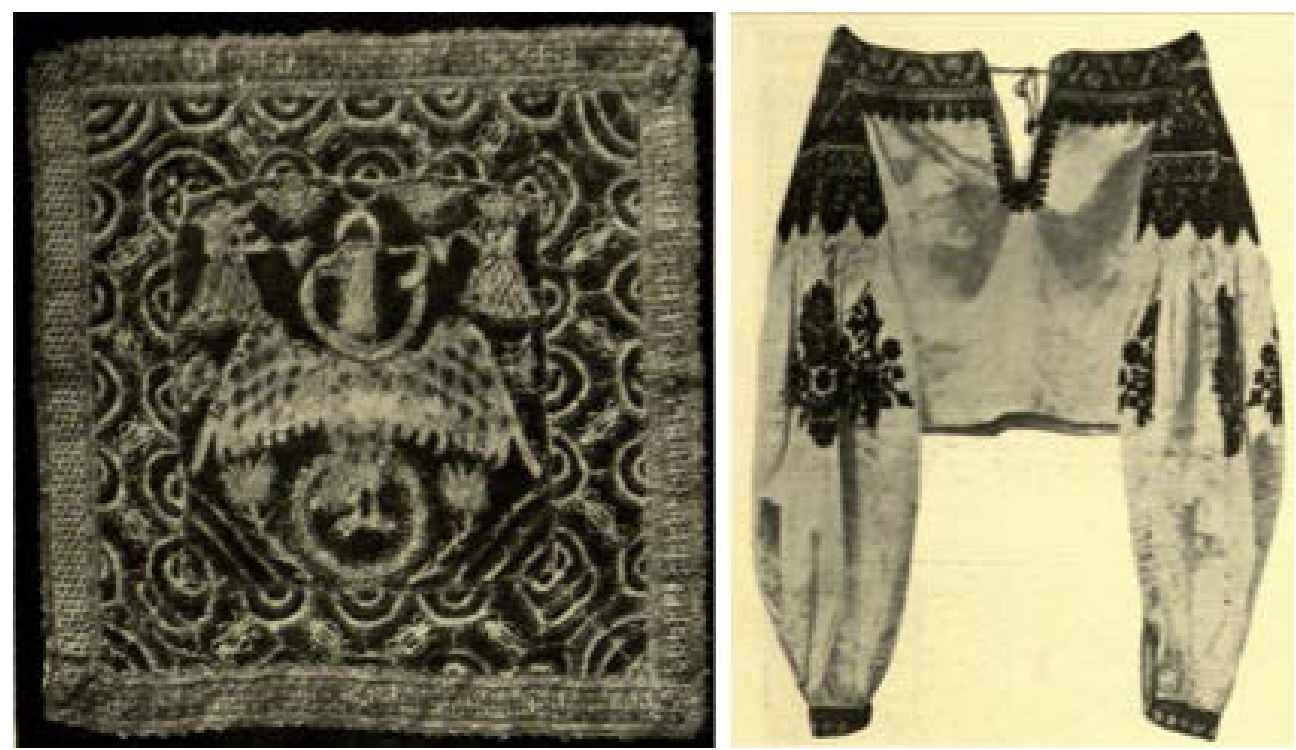

Figuras 6 y 7. Paño de corporales de fondo azul con el centro de encaje de oro y sedas, representando el Evangelio de San Juan, guarnecido de pasamanería y bordados (s. XVI) y camisa bordada en sedas de colores (s. XVII), ambas obras expuestas en la exposición de bordados de 1913 (Anónimo, 1913: 2 y 6). 
La lectura de estas líneas nos permite confirmar la hipótesis de la que partimos al iniciar este estudio: ante la insostenible desigualdad que asolaba a la sociedad española y desde el convencimiento de la eficacia que entrañaba la extensión de la educación en el camino hacia la paridad, por primera vez en nuestro país, un museo aunó, en su planteamiento y proceder, tres funciones -derivadas unas de otrashoy plenamente integradas en la práctica museística. En primer lugar, merced a la adquisición, conservación, catalogación y exhibición ordenada de las colecciones de obras textiles en exposiciones definidas como "artísticas» y no "etnográficas», legitimaba la introducción de las artes populares en el relato de la historia del arte, de forma similar a lo que hacía con la pedagogía y la historia de la ciencia. En este punto jugó un papel muy destacado el propio Cossío, pues si bien participaba del marco filosófico del krauso-positivismo, era contrario a «la distinción krausista entre artes mayores y menores» (Garrido, et al., 1996, p. 165). En segundo lugar, se avanzaba hacia la inclusión de diferentes colectivos sociales -las mujeres, el campesinado, los artesanos, etcétera- en el proceso cultural al darse visibilidad a su legado histórico. Por último, el museo ejercía un papel primordial en la promoción educativa, económica y cultural a través de su implicación en las citadas exposiciones temporales, organizadas en colaboración con entes sociales de diversa naturaleza; de su infiltración en el territorio a través de las colonias escolares; y de la difusión y reinterpretación de sus fondos. Acciones que, además, fueron comprendidas como inherentes a la investigación, hecho que culmina en este ámbito con la creación, en 1931, de "un servicio para la investigación y enseñanza del arte popular en lo referente a las labores femeninas» (García del Dujo, 1985, p. 70).

En suma, el hecho de que el Museo fuese capaz de configurar un espacio en el que obras del pasado convivían con las del presente bajo la supervisión crítica de profesionales de la pedagogía significó un avance muy destacable y que anticipa las prácticas de promoción socioeconómica y cultural que la mayoría de los museos dirigen en la actualidad. Todo ello, junto con las actuaciones que hemos visto a lo largo de este escrito, implicó que, por un lado, el Museo Pedagógico fuese punta de lanza en el desarrollo de la pedagogía, bien a través de la legitimación de la ciencia de la educación, bien mediante la formación de los profesionales y del conjunto de la ciudadanía, erigiéndose en faro para un sector que se debatía "entre la precariedad, la heterogeneidad y la más absoluta desorientación» (García del Dujo, 1985, p. 133). Por el otro lado, el centro significó un hito en la historia de los museos, al configurarse como una estructura eficaz en su tarea de conservar el pasado desde un proceder radicalmente científico y guiada siempre en sus proyectos por un profundo interés humanista en su afán de progreso hacia un futuro más paritario por medio de la acción educativa.

Llegados a este punto, no debe resultar extraño el cierre del Museo en 1941 en el contexto de la depuración ejecutada por los vencedores de la Guerra Civil Española sobre la intelectualidad republicana. Al igual que las Misiones y el resto de 
estructuras derivadas de la ILE, el Museo Pedagógico era una pieza imprescindible del nuevo motor espiritual diseñado por los renovadores para recorrer el camino hacia un nuevo estatuto de la ciudadanía. Un dispositivo que no funcionaba en términos de dominación y diferencia, que ya no dirigía la mirada al futuro desde el pasado, sino de empoderamiento, de equidad, que atendía a lo pretérito desde el porvenir. Por ello, tras la victoria nacional-católica no cabía una reforma del centro museístico, por profunda que esta fuese. La obra de Cossío debía desmontarse hasta sus cimientos. Y así, a la persecución de los institucionistas que lo habían erigido se unió la damnatio memoriae: el depósito de los materiales del Museo en el Instituto San José de Calasanz, hecho que en la práctica supuso su desmantelamiento a través de la inatención, el desorden y el olvido. Pero el triste final del Museo Pedagógico Nacional, contrastado con la actual vigencia de las prácticas museográficas y educativas en él desarrolladas por Manuel Bartolomé Cossío y sus compañeros en pro de la igualdad social, no hace sino ensalzar su importancia histórica. Más aún cuando, aún hoy, aclamadas voces del ámbito de las ciencias humanas insisten en definir a los museos como «cementerios (...) lugares donde se ponen objetos inanimados, muertos» (Bauman, 2007, p. 91). Sirva, a modo de contestación y cierre, el pertinente juicio aportado por el director hace más de un siglo a este debate atemporal: «todo museo debe estar organizado pedagógicamente (...). Todo puede ser o no ser pedagógico, como todo puede ser o no» (Otero, 1994, p. 250).

\section{RECURSOS BIBLIOGRÁFICOS Y DOCUMENTALES}

Abellán García-González, J. L. (1989). Filosofía de la Institución Libre de Enseñanza: El krauso-positivismo. En J. A. Ferrer Benimeli (coord.), Masonería, política y sociedad, Vol. 1 (pp. 405-418). Zaragoza: Centro de Estudios Históricos de la Masonería Española.

Adorno, T. W. (1962). Prismas. La crítica de la cultura y la sociedad. Barcelona: Ediciones Ariel.

Anónimo (1913). Exposición de bordados y encajes populares. Por el Arte. Gaceta de la Asociación de Pintores y Escultores, año I, n. 5. Madrid: Artes Gráficas Mateu. Recuperado el 24 de abril de 2017 de: https://ddd.uab.cat/pub/porart/ porart_a1913m5n5.pdf

Arnaldo, J. (2016). Las visitas escolares al Museo del Prado. En S. Guerrero (ed.), El arte de saber ver. Manuel B. Cossío, la Institución Libre de Enseñanza y el Greco (pp. 261-271). Madrid: Fundación Francisco Giner de los Ríos. 
Arnaldo, J. (2013). El permanente esfuerzo de legitimación intelectual del museo. Museos.es: Revista de la Subdirección General de Museos Estatales, 9-10, 7085.

Arnaldo, J. (Ed.) (2009). Los museos en la educación. Madrid: Fundación Colección Thyssen-Bornemisza.

Arnaldo, J. (2008). El educador de museo. Formación y reconocimiento de una profesión. Amigos de los Museos, 27, 21-25.

Arias, L. (2015). Nuevos planteamientos museográficos en los museos de arte contemporáneo: de las primeras críticas al museo en los albores del siglo XX a los actuales microrrelatos. Complutum, 26(29), 133-143.

Bauman, Z. (2007). Arte, ¿líquido? Madrid: Ediciones sequitur.

Blanco Jiménez, C. (2005). Hacia una cultura universal: algunos precedentes en la enseñanza de la Historia del Arte. Tendencias pedagógicas, n. extra 2, 127-134.

Bolaños, A. (2016, 8 de marzo). La brecha salarial de género en España, la sexta más alta de la Unión Europea. El País. Recuperado el 24 de abril de 2017 de: http:// economia.elpais.com/economia/2016/03/07/actualidad/1457378340_855685.html

Bolaños Atienza, M. (2008). Historia de los museos en España: memoria, cultura, sociedad. Gijón: Trea.

Bolaños Atienza, M. (ed.) (2002). La memoria del mundo. Cien años de museología. 1900-2000. Gijón: Trea.

Brunet, I. y Pastor, I. (2002). Formación, empleabilidad y desigualdades sociales. Témpora, 5, 15-59.

Carta de un maestro. (1918, 9 de junio). La Acción. Diario de la noche. Recuperado el 24 de abril de 2017 de: http://hemerotecadigital.bne.es/issue.vm?id=000351428 5 \&page $=3 \&$ search=\&lang=es

Castells, M. (2004). Space of flows, space of places: Materials for a Theory or Urbanism in the Information Age. En S. Graham (ed.), The Cybercities Reader (pp. 82-93). London: Routledge.

Clair, J. (2010). La paradoja del conservador. Barcelona: Editorial Elba. 
Cossío, M. B. (1929). De su jornada (fragmentos). Madrid: imprenta de Blass S.A.

Cossío, M. B. (1884). Algunos vacíos del Museo del Prado. Boletín de la Institución Libre de Enseñanza, 177, 187-189.

España, el país más desigual de la $\operatorname{OCDE}$ (2016, 18 de enero). La Vanguardia. Recuperado el 24 de abril de 2017 de: http://www.lavanguardia.com/ economia/20160118/301484073871/espana-desigual-ocde.html

Fernández, M. (1990). No hay más cera que la que arde: educación, formación y empleo en España en el umbral de los 90. Revista Española de Investigaciones Sociológicas, 293, 7-52.

Fernández, M. (2003). Los museos: espacios de cultura, espacios de aprendizaje. IBER. Didáctica de las Ciencias Sociales, Geografía e Historia, 36, 55-61.

García, M. (2015). Días de emoción intensa. Sobre el entusiasmo y sus propietarios. Historia y Memoria de la Educación, 2, 73-96.

García Fernández, I. (2015). El papel de los museos en la sociedad actual: discurso institucional o museo participativo. Complutum, 26(2), 39-47.

García del Dujo, Á. (1985). Museo Pedagógico Nacional (1882-1941). Teoría educativa y desarrollo histórico. Salamanca: Ediciones de la Universidad de Salamanca.

Garrido González, J. Á. y Pinto Martín, A. (1996). La educación estética en la Institución Libre de Enseñanza. Revista Interuniversitaria de Formación del Profesorado, 27, 151-166.

Hernández Fraile, P. (1987). Museo Pedagógico Nacional. Boletín de la ANABAD, 37, 615-620.

Herranz, A. (2017, 27 de julio). Desigualdad salarial y salarios más bajos, por ser mujer. El Diario. Recuperado el 24 de abril de 2017 de: http://www.eldiario.es/ desigualdadblog/desigualdad_de_genero-desigualdad_salarial-derechos_de_las_ mujeres_6_541455852.html

Jiménez-Landi Martínez, A. (1996). La Institución Libre de Enseñanza y su ambiente. Tomo IV: Periodo de expansión influyente. Madrid: Ministerio de Educación y Cultura. 
Jiménez-Landi Martínez, A. (1984). Las excursiones de la Institución. Estudios turísticos, 83, 101-108.

Lorenzo Vicente, J. A. (1999). La formación del pedagogo laboral. Revista Complutense de Educación, 10(1), 127-158.

Marco Tello, P. (2007). El diálogo entre el museo y la formación de maestros. En R. Calaf, O. Fontal y R. Valle (coords.), Museos de Arte y Educación. Construir patrimonios desde la diversidad (pp. 387-406). Gijón: Ediciones Trea, S. L.

Martín Baró, A. (2014). Panorama de la educación 2014. Indicadores de la OCDE. Madrid: Fundación Santillana. S. L.

Molero Pintado, A. (1985). La Institución Libre de Enseñanza: Un proyecto español de renovación pedagógica. Madrid: Anaya.

Núñez, C. E. (2005). Educación. En A. Carreras y X. Tafunell (eds.), Estadísticas históricas de España, siglos XIX-XX. Volumen 1 (pp. 155-244). Madrid: Fundación BBVA.

Otero Urtaza, E. (1994). Manuel B. Cossío: pensamiento pedagógico y acción educativa. Madrid: Centro de Publicaciones del Ministerio de Educación y Ciencia.

Otero Urtaza, E. (ed.) (2007). El maestro, la escuela y el material de enseñanza y otros escritos. Madrid: Secretaría General Técnica del Ministerio de Educación y Ciencia y Biblioteca Nueva, S.L.

Otero Urtaza, E. (2012). Manuel B. Cossio's 1882 Tour of European Education Museums. Paedagogica Historica: International Journal of the History of Education, 48(2), 197-213.

Pomian, K. (2007). Sobre la historia. Madrid: Cátedra.

Riviére, G. H. (1993). La Museología / Textos y testimonios. Madrid: Akal.

Valéry, P. (1999). Le problème des musées. En J. L. Arántegui (ed.), Piezas sobre arte (pp. 137-140). Madrid: Visor, La balsa de la medusa.

VV. AA. (1985). Manuel B. Cossío y el Museo Pedagógico, 1935-1985. Madrid: Comunidad de Madrid. 
Valverde, Marqués de (1915). Catálogo de la exposición de lencería y encajes españoles del siglo XVI al XIX / Por el Marqués de Valverde. Madrid: Artes Gráficas Mateu. Recurso disponible en la web (consultado el 27-04-2016): http://ddd.uab.cat/pub/llibres/1915/73834/catexplen_a1915@mnac.pdf 